\title{
Performance Prediction Analysis for Aero-Naut CAM Folding Propellers and its Application into CREATeV Solar Aircraft
}

\author{
by \\ Hyunwoo Kim \\ under supervision of \\ Dr. Goetz Bramesfeld
}

AER 870

Aerospace Engineering Thesis

\author{
Ryerson University \\ Department of Aerospace Engineering \\ Toronto, Ontario, Canada \\ April 20, 2021
}




\begin{abstract}
This paper investigates the performance prediction method for Aero-Naut CAM folding propellers through parametric studies of existing wind tunnel testing data. The application of the propeller into CREATeV ultra-long-endurance unmanned solar aircraft necessitated the availability of accurate performance estimates for its propeller-motor configurations. Performance coefficient prediction method based on scaling relationship of propeller geometry is discussed along with motor efficient prediction method and iterative propeller-motor performance optimization. Several important observations regarding performance scaling effect of Aero-Naut folding propellers and its impact on performance optimization are discussed. The resulting optimized propeller selections are proposed which would enhance mission capability of CREATeV. Finally, future work considerations and concluding remarks of the analysis is presented.
\end{abstract}




\section{Acknowledgement}

The author would like to thank Dr. Goetz Bramesfeld for the opportunity for the undergraduate thesis as well as his guidance, support, and patience when needed.

The author would also like to acknowledge and express gratitude to William Bissonette and members of Ryerson Applied Aerodynamics Laboratory of Flight (RAALF) for providing valuable test data and various other information regarding Aero-Naut CAM folding propeller and Clean Renewable Energy Aerial Test Vehicle (CREATeV) project.

Additional clarifications regarding wind tunnel test data conducted at University of Illinois at Urbana - Champaign (UIUC) were provided by Or Dantsker, M. Sc., and Dr. Michael S. Selig. The author acknowledges and would like to thank their support.

Finally, the author is ever grateful for the family and friends from various communities of faith, academics, and whether it be on-line or off-line. Your never-ending encouragement and support had shaped me who I am. Thank you. 


\section{Table of Contents}

Abstract

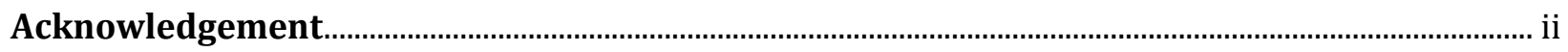

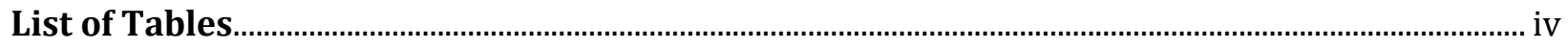

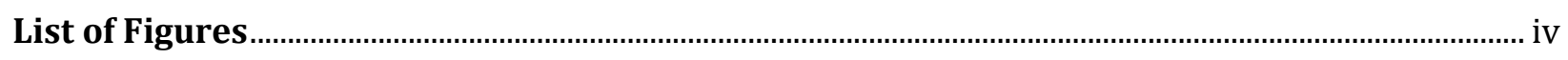

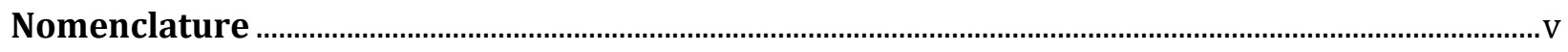

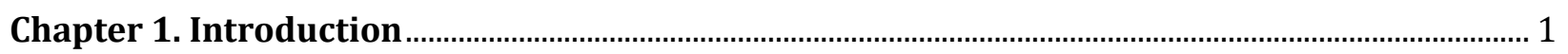

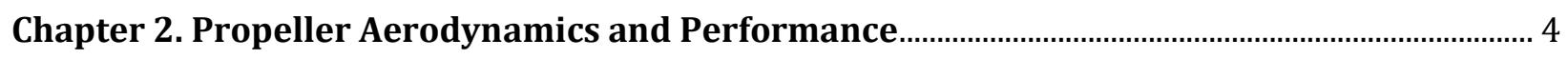

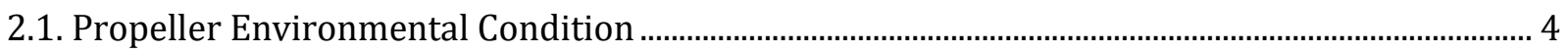

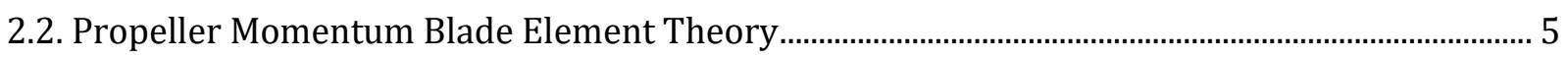

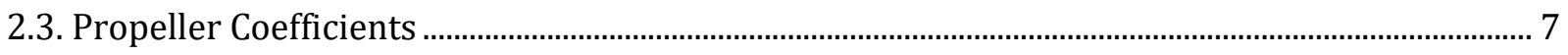

Chapter 3. Performance Prediction Methodology ……........................................................................ 8

3.1. Thrust and Power Coefficient Scaling Relations Prediction ................................................................ 8

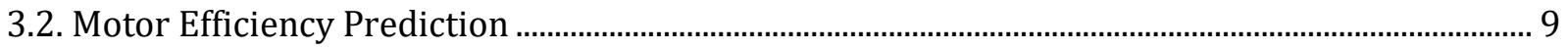

3.3. Iteration Method and Propeller-Motor Performance Optimization...................................................11

Chapter 4. Performance Prediction Results .......................................................................................13

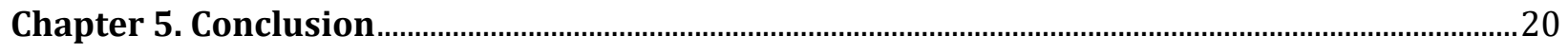

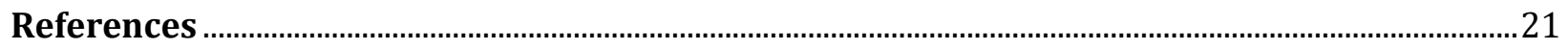

Appendix A: Thrust and Power Coefficient Curve Fit Equations ........................................................22

Appendix B: Performance Graphs of Analyzed Propellers .....................................................................23 


\section{List of Tables}

Table 1: Coefficients for Motor Efficiency Equation.

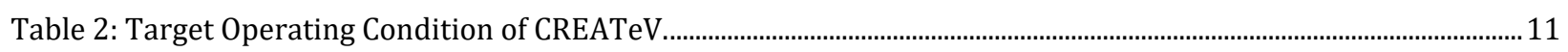

Table 3: Theoretical Optimum Propellers for Maximum Efficiency ………………………………………………………....19

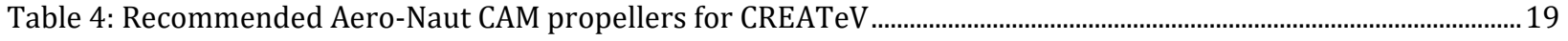

Table 5: Thrust Coefficient Curve Fit....................................................................................................................................................22

Table 6: Power Coefficient Curve Fit ........................................................................................................................................ 22

\section{List of Figures}

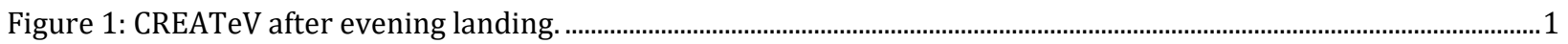

Figure 2: Aero-Naut folding propeller blades...............................................................................................................................

Figure 3: Definitions of elements at propeller blade element at radius station, $\mathrm{r}$...................................................................5

Figure 4: Surface fit implementation for T-MOTOR U7-V2.0 efficiency.................................................................................

Figure 5: Simplified propeller-motor performance prediction process flow chart..................................................................12

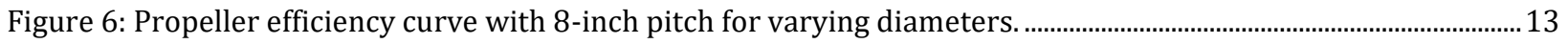

Figure 7: Thrust coefficient curves of propellers with 8-inch pitch for varying diameters..................................................14

Figure 8: Power coefficient curves of propellers with 8-inch pitch for varying diameters..................................................14

Figure 9: Propeller efficiency curves of propellers with varying P/D ratio............................................................................15

Figure 10: Thrust coefficient curves of propellers with varying P/D ratio. ............................................................................... 16

Figure 11: Power coefficient curves of propellers with varying P/D ratio.................................................................................. 16

Figure 12: Estimated maximum propeller efficiency for varying propeller geometry........................................................... 18

Figure 13: Estimated maximum overall efficiency for varying propeller geometry...............................................................18

Figure 14: (a) propeller efficiency, (b) thrust coefficient, and (c) power coefficient of propeller with $P / D=0.4 \ldots \ldots . .23$

Figure 15: (a) propeller efficiency, (b) thrust coefficient, and (c) power coefficient of propeller with $\mathrm{P} / \mathrm{D}=0.5 \ldots \ldots . .24$

Figure 16: (a) propeller efficiency, (b) thrust coefficient, and (c) power coefficient of propeller with $\mathrm{P} / \mathrm{D}=0.6 \ldots \ldots . .25$

Figure 17: (a) propeller efficiency, (b) thrust coefficient, and (c) power coefficient of propeller with $\mathrm{P} / \mathrm{D}=0.7 \ldots \ldots . .26$

Figure 18: (a) propeller efficiency, (b) thrust coefficient, and (c) power coefficient of propeller with $\mathrm{P} / \mathrm{D}=0.8 \ldots \ldots . .27$

Figure 19: (a) propeller efficiency, (b) thrust coefficient, and (c) power coefficient of propeller with $\mathrm{P} / \mathrm{D}=0.846 . .28$

Figure 20: (a) propeller efficiency, (b) thrust coefficient, and (c) power coefficient of propeller with $\mathrm{P} / \mathrm{D}=0.9 \ldots \ldots . .29$

Figure 21: (a) propeller efficiency, (b) thrust coefficient, and (c) power coefficient of propeller with $\mathrm{P} / \mathrm{D}=1.1 \ldots \ldots . .30$

Figure 22: (a) propeller efficiency, (b) thrust coefficient, and (c) power coefficient of propeller with $P / D=1.2 \ldots \ldots . . .31$ 


\section{Nomenclature}

CREATeV = Clean Renewable Energy

Aerial Test Vehicle

RAALF = Ryerson Applied Aerodynamics

Laboratory of Flight

$\mathrm{SL}=$ sea level

$\mathrm{UAV}=$ unmanned aerial vehicle

UIUC = University of Illinois at Urbana -

Champaign

$\mathrm{c}=$ propeller section chord

$C_{d}=$ propeller section drag coefficient

$C_{l}=$ propeller section lift coefficient

$C_{l_{\alpha}}=$ propeller section lift curve slope

$C_{P}=$ propeller power coefficient

$C_{T}=$ propeller thrust coefficient

$\mathrm{D}=$ propeller diameter

$h_{\rho}=$ density altitude

$\mathrm{J}=$ advance ratio

$\mathrm{L}=$ propeller lift

$\mathrm{n}=$ revolution per second

$n_{r p m}=$ revolution per minute $\mathrm{p}=$ pressure

$\mathrm{P}=$ propeller power

$\mathrm{P} / \mathrm{D}=$ pitch-to-diameter ratio

$Q=$ propeller torque

$r=$ propeller radial station

$\mathrm{R}=$ propeller radius

$R_{\text {gas }}=$ universal gas constant

$T$ = temperature

$\mathcal{T}=$ propeller thrust

$\mathrm{V}=$ freestream velocity

$V_{e}=$ effective resultant velocity

$\alpha_{i}=$ propeller induced angle of attack

$\beta=$ propeller blade pitch angle

$\eta_{\text {motor }}=$ motor efficiency

$\eta_{\text {prop }}=$ propeller efficiency

$\eta_{t}=$ overall (total) efficiency

$\rho=$ density

$\phi=$ propeller helix angle 


\section{Chapter 1. Introduction}

Ryerson University's Clean Renewable Energy Aerial Test Vehicle (CREATeV), shown in Fig. 1, is an ultra-long-endurance, solar-powered unmanned composite aircraft with the goal of continuous sustained flight endurance of 60 days. Along the upper surface of 6.28metre-long wing lies 96 solar cells which would recharge the battery during hours of daylight, and would sustain the flight during nightfall for maximum of 12 hours [1]. A unique mission profile of CREATeV where it needs to satisfy optimal flight conditions of ultra-long endurance flight while meeting rigorous power consumption constraints drives optimization of propeller-motor performance an important aspect for its mission success. Dantsker et al. [2] estimated that about $52 \%$ of the total electrical power consumption of computationally intensive small unmanned aerial vehicles (UAVs) is caused by propulsion. Therefore, there exists a significant potential for performance improvement from achieving greater overall propulsion efficiency, benefitting wide variety of high-performance and general-use UAVs as well.

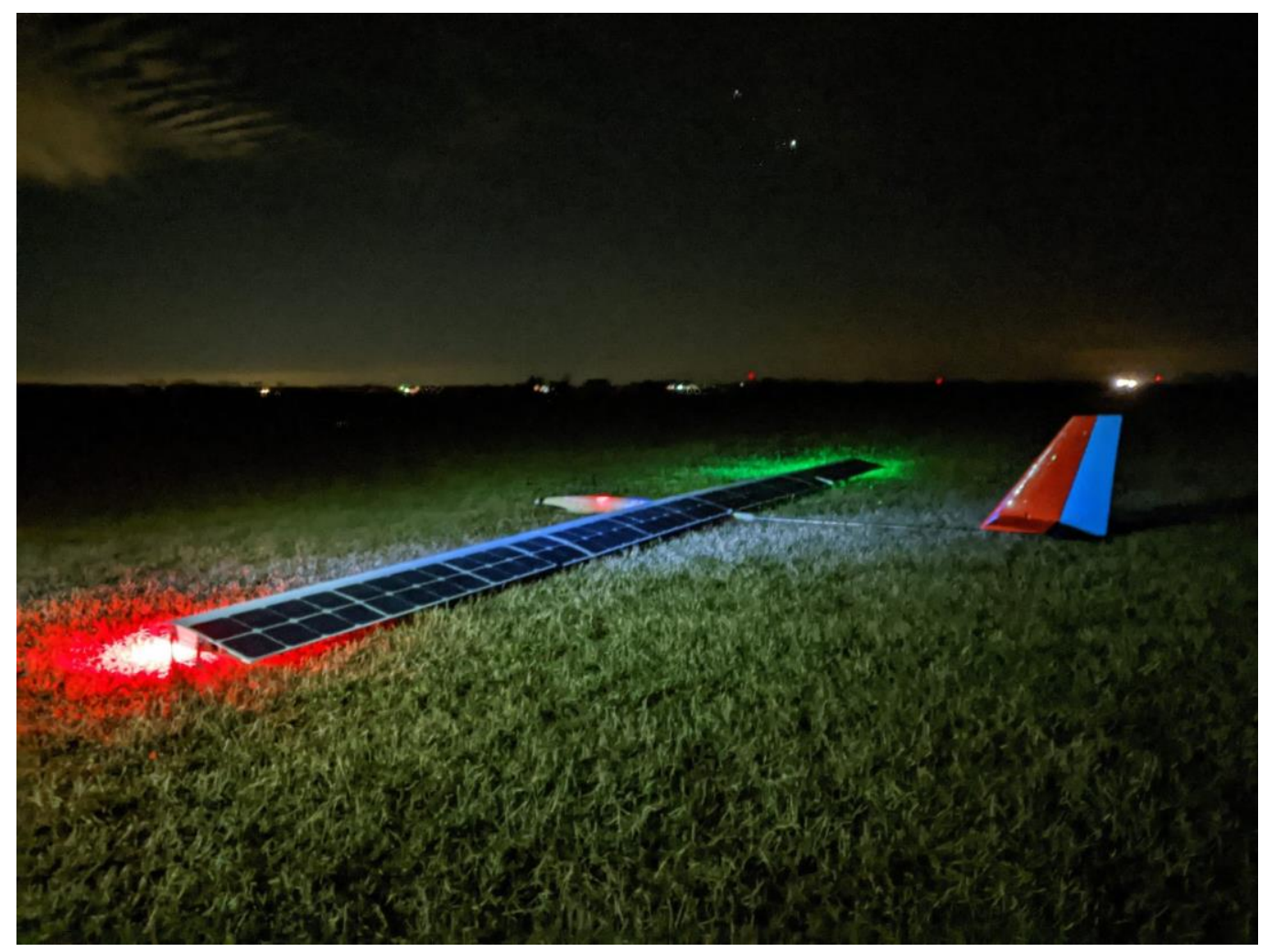

Figure 1: CREATeV after evening landing. [3] 
Based on current wind tunnel analysis conducted at Ryerson Applied Aerodynamics Laboratory of Flight (RAALF), Aero-Naut CAM folding propellers with T-MOTOR U7-V2.0 $280 \mathrm{KV}$ motor were selected as a suitable choice for CREATeV's propulsion system - 18X9 and 20X10 propellers in particular. Examples of the folding propeller blades can be seen in Fig. 2. Although wide range of Aero-Naut CAM folding propellers were recently tested at University of Illinois at Urbana-Champaign (UIUC) by Dantsker et al. [4], no published propeller test data was found for diameter greater than 16 inches. Independent wind tunnel testing remains a viable and reliable option for obtaining propeller performance results, propeller optimization process would require numerous diameters and pitch geometries to be tested for proper performance comparison. Such endeavour quickly becomes too costintensive due to time-consuming and labour-intensive nature of conducting wind tunnel testing in addition to the expensive wind tunnel machinery operating costs.

More cost-effective, rapid and relatively accurate analysis methods have been proven for different propeller models where Jessa [5] determined low-Reynolds-number scaling relations of aerodynamics and propeller performance for varying rotor diameter of identical pitch for T-MOTOR carbon fiber rotors. For an identical pitch geometry of different diameters, there existed a near-identical chord and twist distributions and near-identical aerodynamics and performance coefficients.

This report investigates an analysis into a scaling relation concerning performance of Aero-Naut CAM folding propellers through parametric studies of published wind tunnel data. The determined scaling relations would be utilized in determining optimum propeller-motor candidates for CREATeV propulsion system with primary focus on efficiency. The governing theories of propeller aerodynamics and performance are explored in Chapter 2, and detailed performance prediction methodology through scaling relations using wind tunnel test results are explained in Chapter 3. The summary of analysis results regarding propeller scaling relation and propeller performance are presented in Chapter 4, along with a conclusion and summary of future works in Chapter 5. 


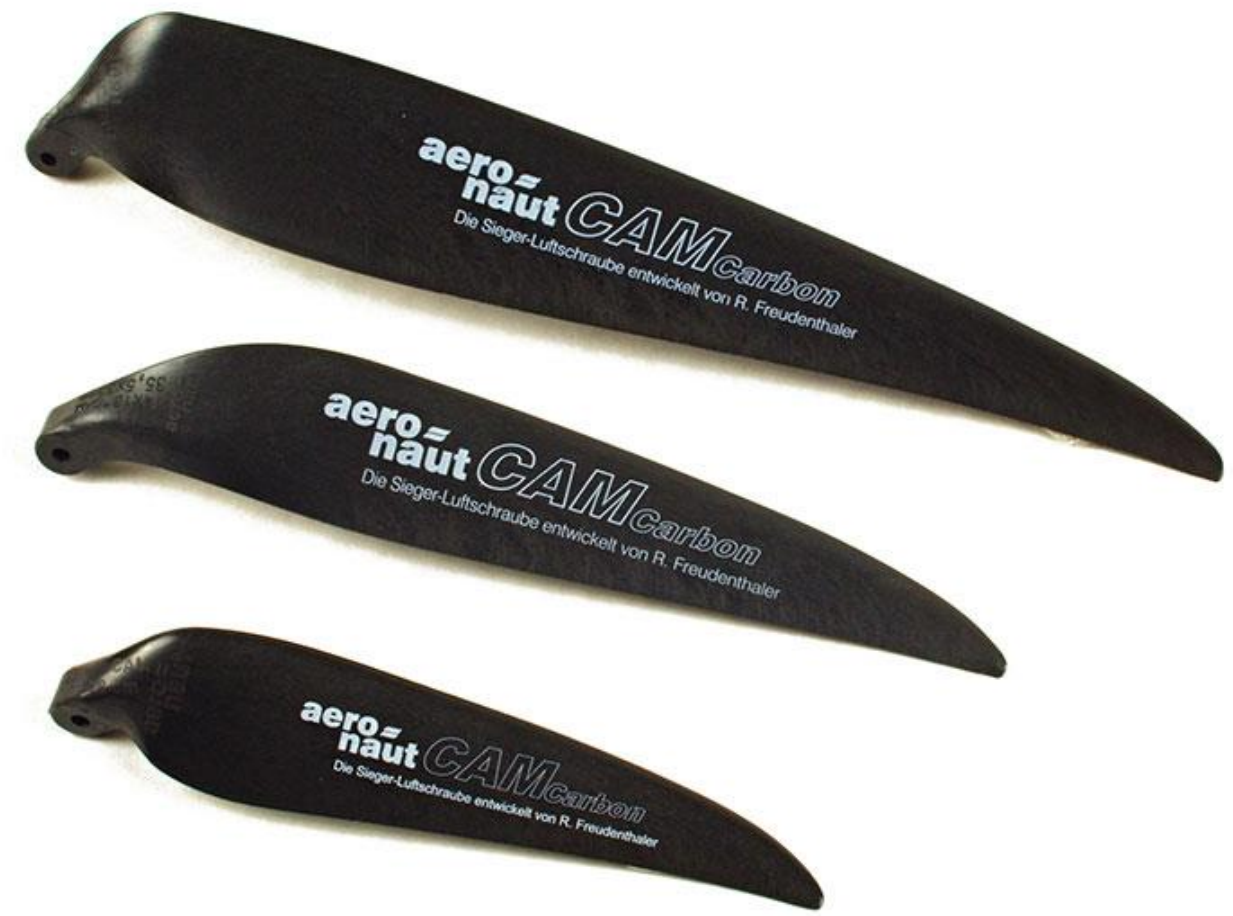

Figure 2: Aero-Naut folding propeller blades. [6] 


\section{Chapter 2. Propeller Aerodynamics and Performance}

In order to effectively predict the performance of propellers, fundamental understanding of propeller aerodynamics and its correlation with propeller performance was essential. Environmental operating condition for propeller would be defined in section 2.1, and important governing relations for propeller aerodynamics would be examined using momentum-blade element theory in Section 2.2. Finally, sets of propeller performance equations consisted of coefficients would be defined in Section 2.3.

\subsection{Propeller Environmental Condition}

Accurate environmental model that closely resembles target flight condition was imperative for obtaining any meaningful propeller performance prediction results.

If air is assumed to behave as an ideal gas, and if two parameters are known from temperature, pressure, and density, ideal gas law can be used to determine atmospheric properties of interest. The ideal gas law is defined as [7],

$$
p=\rho R_{g a s} T
$$

Additionally, if target flight altitude is known, density of operating condition could be estimated from density altitude definition provided by Gudmundsson, for altitudes below $36.089 \mathrm{ft}(11,000 \mathrm{~m})$ and provided in feet [7].

$$
\rho=\rho_{S L}\left[1-\frac{h_{\rho}}{145442}\right]^{\frac{1}{0.234957}}
$$




\subsection{Propeller Momentum Blade Element Theory}

For any propellers of varying size, pitch numbers, and model series, the blade element characteristics of given propeller plays an important role in determining its performance. As shown in Fig. 3, the propeller blade element is selected by examining the cross-section of incremental radius, $d r$, located at radius station $r$ away from the hub.

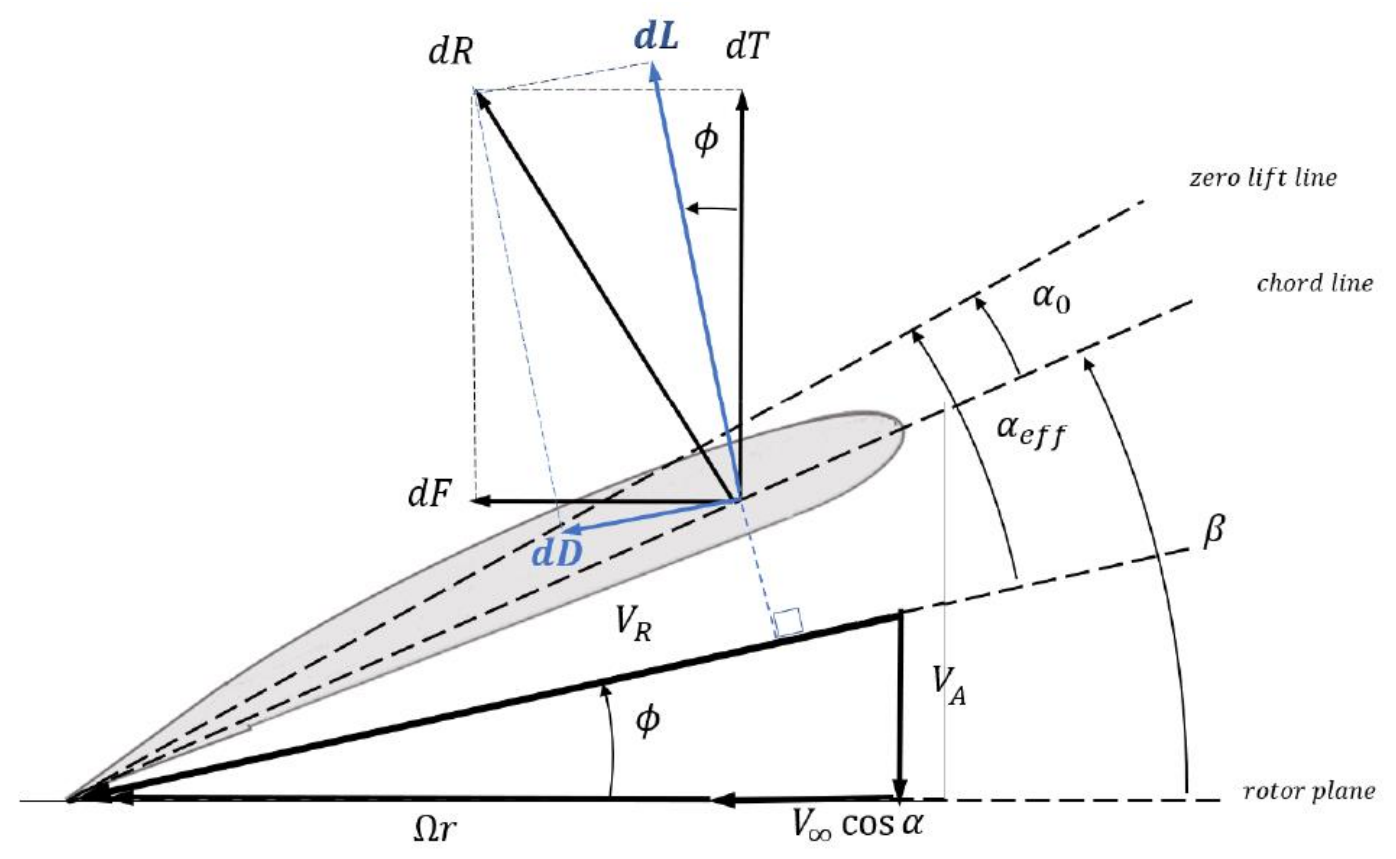

Figure 3: Definitions of elements at propeller blade element at radius station, $r$ [5].

The pitch, and pitch-to-diameter ratio (P/D) of the given propeller, respectively, are defined as,

$$
\begin{aligned}
& P=2 \pi r \tan \beta \\
& \frac{P}{D}=\pi\left(\frac{r}{R}\right) \tan \beta
\end{aligned}
$$


And incremental thrust and torque of blade element, respectively, are defined as,

$$
\begin{aligned}
& d \mathcal{T}=d L \cos \left(\varphi+\alpha_{i}\right)-d D \sin \left(\varphi+\alpha_{i}\right) \\
& d Q=r\left\{d L \sin \left(\varphi+\alpha_{i}\right)+d D \cos \left(\varphi+\alpha_{i}\right)\right\}
\end{aligned}
$$

Where,

$$
\begin{aligned}
& d L=\frac{1}{2} \rho V_{e}{ }^{2} c C_{l} d r \\
& d D=\frac{1}{2} \rho V_{e}{ }^{2} c C_{d} d r \\
& C_{l}=C_{l_{\alpha}}\left(\beta-\varphi-\alpha_{i}\right) \\
& C_{d}=f\left(C_{l}\right)
\end{aligned}
$$

If the effect of induced angle of attack of propeller $\left(\alpha_{i}\right)$ is assumed to be small and therefore neglected [8],

$$
\begin{aligned}
& d L \& d D \approx f(\beta, \varphi) \\
& \therefore d \mathcal{T} \& d Q \approx f(\beta, \varphi)
\end{aligned}
$$

Equations (4a) and (4b) are then integrated over the propeller radius to obtain estimated thrust and torque [8]. From quick examination of Equation (6b), it can be demonstrated that relationship exists between propeller performance and propeller pitch, rotational speed, and freestream velocity. Therefore, favourable analysis result is expected from parametric performance estimation method of propeller based on varying propeller geometries and operating conditions. 


\subsection{Propeller Coefficients}

Propeller performance results are published in non-dimensional coefficients by reducing geometric, velocity, and environmental parameters. The non-dimensionalized approach enables appropriate performance comparison for propellers of varying geometries and operating conditions.

Propeller power is determined by propeller torque and its angular velocity:

$$
P=2 \pi n Q
$$

Non-dimensionalized power and thrust coefficients, respectively, are determined using,

$$
\begin{aligned}
C_{p} & =\frac{P}{\rho n^{3} D^{5}} \\
C_{T} & =\frac{\mathcal{T}}{\rho n^{2} D^{4}}
\end{aligned}
$$

Freestream and rotational velocity terms can be non-dimensionalized in terms of advance ratio, $J$, and is determined as,

$$
J=\frac{V}{n D}
$$

The efficiency of the propeller is defined as,

$$
\eta_{\text {prop }}=\frac{\mathcal{T V}}{P}=\frac{C_{T} J}{C_{P}}
$$

Finally, if motor efficiency at operating condition is known, the overall efficiency at operating condition is defined as,

$$
\eta_{t}=\eta_{\text {motor }} \eta_{\text {prop }}
$$

Where $\eta_{\text {motor }}$ denotes the efficiency of the motor. 


\section{Chapter 3. Performance Prediction Methodology}

Implementation methods for performance analysis of Aero-Naut CAM folding propellers are discussed in this chapter. Thrust and power coefficient curve prediction method for various propeller pitch geometry is described in Section 3.1. Motor efficiency prediction method for various target flight operating conditions based on wind tunnel testing data conducted by RAALF is described in Section 3.2. Finally, iterative propeller performance solution prediction method is presented in Section 3.3. MATLAB programs were implemented for conducting aforementioned predictions because of their robustness and flexibility.

\subsection{Thrust and Power Coefficient Scaling Relations Prediction}

In order to accurately predict thrust and power coefficients of Aero-Naut folding propellers with various size and geometry, a performance scaling relationship based on propeller geometric parameters must be identified and validated. As an example, Jessa [5] identified performance scaling relations of T-motor rotors with identical propeller pitch geometries, which were also found to have identical pitch number for various propeller diameters. For Aero-Naut folding propellers, Dantsker et al. [4] identified a trend where thrust, power, and efficiency coefficients depend on $\mathrm{P} / \mathrm{D}$ ratio, suggesting a possible existence of performance scaling relationship with propeller geometry.

However, difficulties in determining the performance scaling relationship for AeroNaut CAM folding propellers were also identified. Dantsker et al. [4] had investigated geometric characteristics of the folding propellers of various diameter and pitch sizes, of which they discovered that for varying pitch number and P/D ratio for given diameter, the propeller blade geometry was different and unique from one another.

Therefore, the level of validity and applicability of performance scaling relations for different propeller models had to be understood and demonstrated. To do so, effects of propeller pitch number and propeller $\mathrm{P} / \mathrm{D}$ ratio on performance coefficients were investigated when analyzing performance scaling relationship for Aero-Naut CAM folding propellers. For compiling propeller coefficient values in determining performance scaling 
relationship, wind tunnel test results recorded at UIUC was utilized due to the availability for wide variance of propeller size and pitch [4]. Once the characteristic parameter was determined, the corresponding thrust and power coefficient functions were estimated by plotting series of appropriate propeller data of varying diameter, then extrapolating equation of $2^{\text {nd }}$ to $4^{\text {th }}$ order using 'polyfit' function on MATLAB.

\subsection{Motor Efficiency Prediction}

The efficiency curve of T-MOTOR U7-V2.0 280KV motor for CREATeV was obtained by analyzing wind tunnel testing data of various propellers conducted at RAALF. A surface fit estimation of motor efficiency was constructed via MATLAB using propeller torque and motor RPM of test conditions, and its plot can be seen in Fig. 4. It was determined that the $4^{\text {th }}$-order approximation would result in accurate surface fit model at its expected operating test conditions. A mathematical expression of the surface plot as functions of propeller torque and motor RPM was obtained through curve fit using MATLAB, and its mathematical expression is presented in Equation (12) and Table 1.

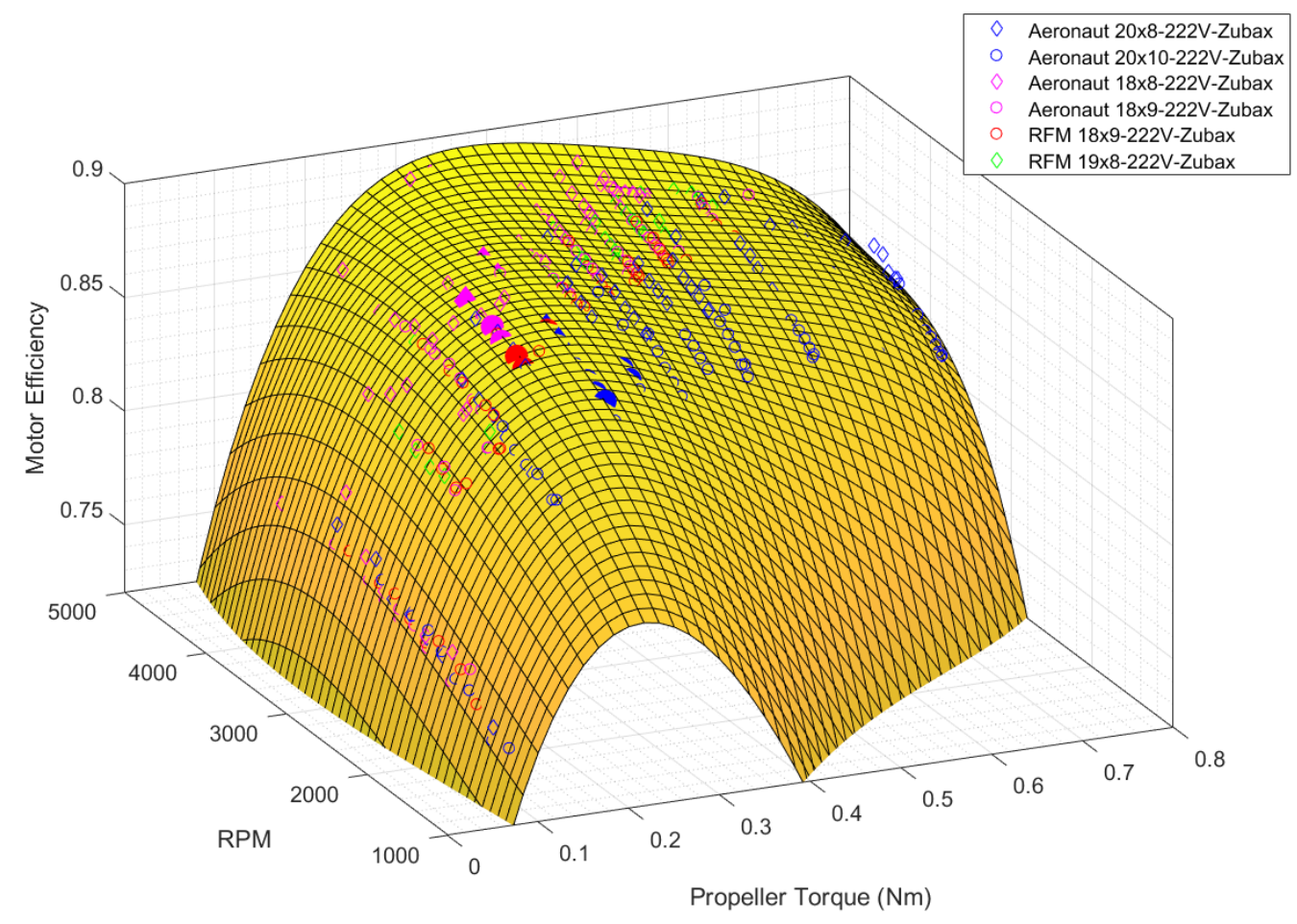

Figure 4: Surface fit implementation for T-MOTOR U7-V2.0 efficiency. 


$$
\begin{aligned}
& \eta_{\text {motor }}\left(Q, n_{r p m}\right)=p_{00}+p_{10} Q+p_{01} n_{r p m}+p_{20} Q^{2} \\
& +p_{11} Q n_{r p m}+p_{02} n_{r p m}{ }^{2}+p_{30} Q^{3}+p_{21} Q^{2} n_{r p m}+p_{12} Q n_{r p m}{ }^{2}+p_{03} n_{r p m}{ }^{3} \\
& +p_{40} Q^{4}+p_{31} Q^{3} n_{r p m}+p_{22} Q^{2} n_{r p m}{ }^{2}+p_{13} Q n_{r p m}{ }^{3}+p_{04} n_{r p m}{ }^{4}
\end{aligned}
$$

\begin{tabular}{|c|c|}
\hline Coefficient & Value \\
\hline$p_{00}$ & 0.5872 \\
\hline$p_{10}$ & 2.163 \\
\hline$p_{01}$ & $-7.553 e-6$ \\
\hline$p_{20}$ & -8.457 \\
\hline$p_{11}$ & 0.000169 \\
\hline$p_{02}$ & $1.868 \mathrm{e}-8$ \\
\hline$p_{30}$ & 8.403 \\
\hline$p_{21}$ & 0.001117 \\
\hline$p_{12}$ & $-1.365 e-7$ \\
\hline$p_{03}$ & $-2.862 \mathrm{e}-12$ \\
\hline$p_{40}$ & -4.73 \\
\hline$p_{31}$ & 0.0003115 \\
\hline$p_{22}$ & $-2.028 e-7$ \\
\hline$p_{13}$ & $2.528 \mathrm{e}-11$ \\
\hline$p_{04}$ & $-1.806 e-16$ \\
\hline
\end{tabular}

Table 1: Coefficients for Motor Efficiency Equation. 


\subsection{Iteration Method and Propeller-Motor Performance Optimization}

Table 2: Target Operating Condition of CREATeV.

\begin{tabular}{|c|c|}
\hline Thrust(T) $[\mathbf{N}]$ & $5<\mathcal{T}<7$ \\
\hline Airspeed $(\mathbf{V})\left[\frac{m}{s}\right]$ & $8<V<11$ \\
\hline Density Altitude $\left(\boldsymbol{h}_{\boldsymbol{\rho}}\right)[\mathbf{f t}]$ & 2,000 \\
\hline
\end{tabular}

Target optimum thrust and freestream velocity, and its target density altitude of CREATeV are expected to fall within a range given in Table 2. Given its target operating conditions and diameter, Equation (8b) can be re-arranged into homogenous polynomial equation function of $n$ and be solved for roots. For a relative rapid convergence for the iteration simplicity, a modified Newton-Raphson method suggested by McDougall and Wotherspoon [8] was utilized:

$$
\begin{aligned}
& x_{0}{ }^{*}=x_{0} \\
& x_{1}=x_{0}-\frac{f\left(x_{0}\right)}{f^{\prime}\left(x_{0}\right)}
\end{aligned}
$$

For $k \geq 1$,

$$
\begin{aligned}
& x_{k}{ }^{*}=x_{k}-\frac{f\left(x_{k}\right)}{f^{\prime}\left(\frac{1}{2}\left[x_{k-1}+x_{k-1}{ }^{*}\right]\right)} \\
& x_{k+1}=x_{k}-\frac{f\left(x_{k}\right)}{f^{\prime}\left(\frac{1}{2}\left[x_{k}+x_{k}{ }^{*}\right]\right)}
\end{aligned}
$$

Where, if $x=n$,

$$
\begin{aligned}
& f(n)=\left(\rho D^{4} C_{T}\right) n^{2}-\mathcal{T} \\
& f^{\prime}(n)=2\left(\rho D^{4} C_{T}\right) n
\end{aligned}
$$


Once value of $n$ is obtained through modified Newton-Raphson method, power coefficient and advance ratio of the propeller were estimated using Equations (8a) and (9), respectively. Its propeller efficiency was calculated using Equation (10), along with expected propeller torque through Equation (7).

Motor efficiency was determined using Equation (12) in Section 3.2., with overall efficiency being a simple product of propeller and motor efficiency as per Equation (11). Its maximum overall efficiency can easily be isolated and be plotted for varying diameters, and was iterated for varying range of characteristic geometry parameters. A simplified representation of the propeller-motor performance prediction is shown in Fig. 5.

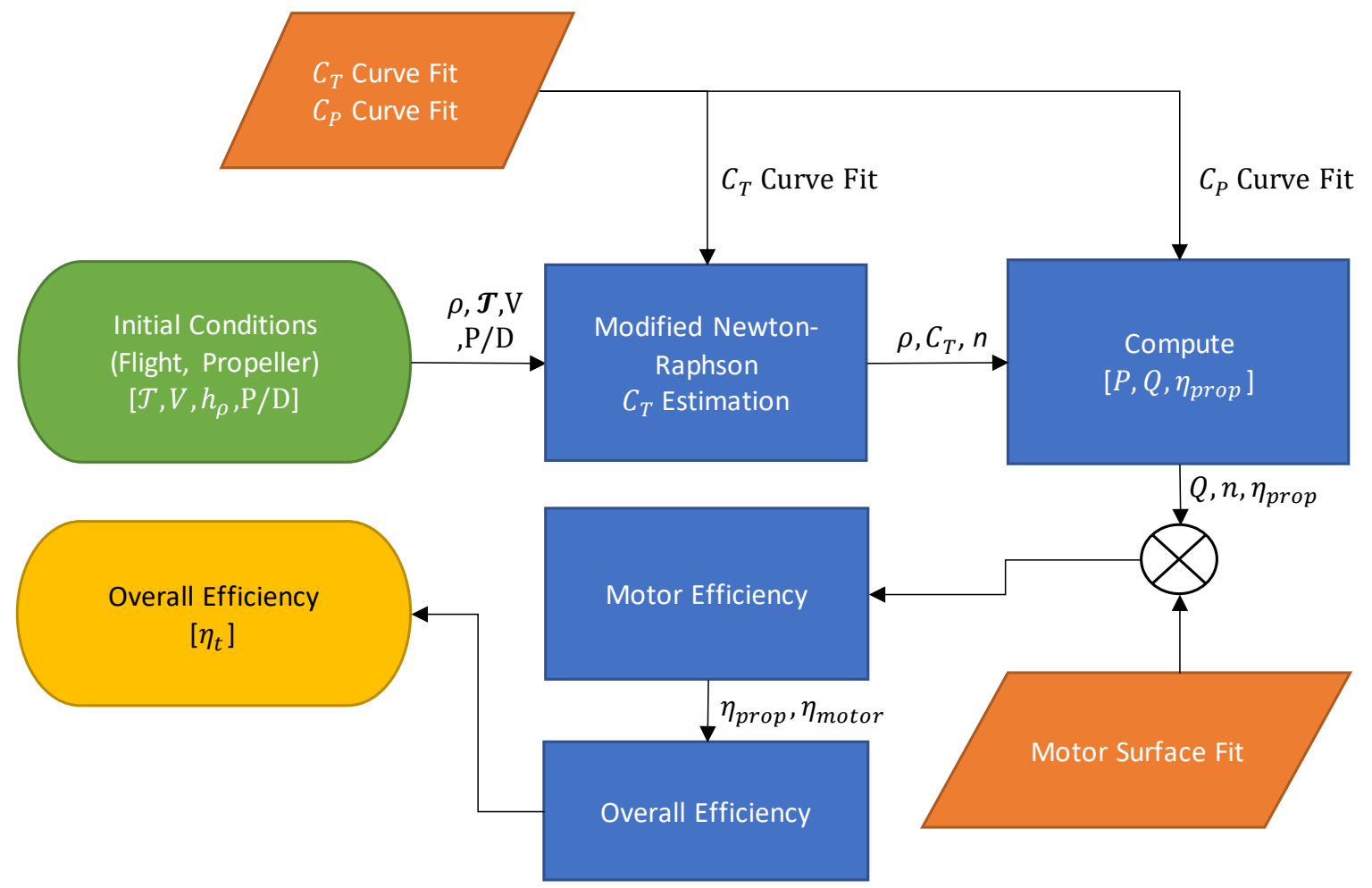

Figure 5: Simplified propeller-motor performance prediction process flow chart. 


\section{Chapter 4. Performance Prediction Results}

Data from 35 Aero-Naut CAM folding propellers with diameters ranging from 10 to 16 inches were used for the analysis. Parametric analysis in relations to propeller pitch number yielded relative wide discrepancy in propeller efficiency as well as thrust and power coefficients, which is presented in Fig. 6 through 8, respectively. The results are in line with Aero-Naut propellers' unique geometric profiles, suggesting that unlike Jessa's analysis method [5], relatively poor performance scaling relations exist based on propeller pitch number for Aero-Naut CAM folding propellers.

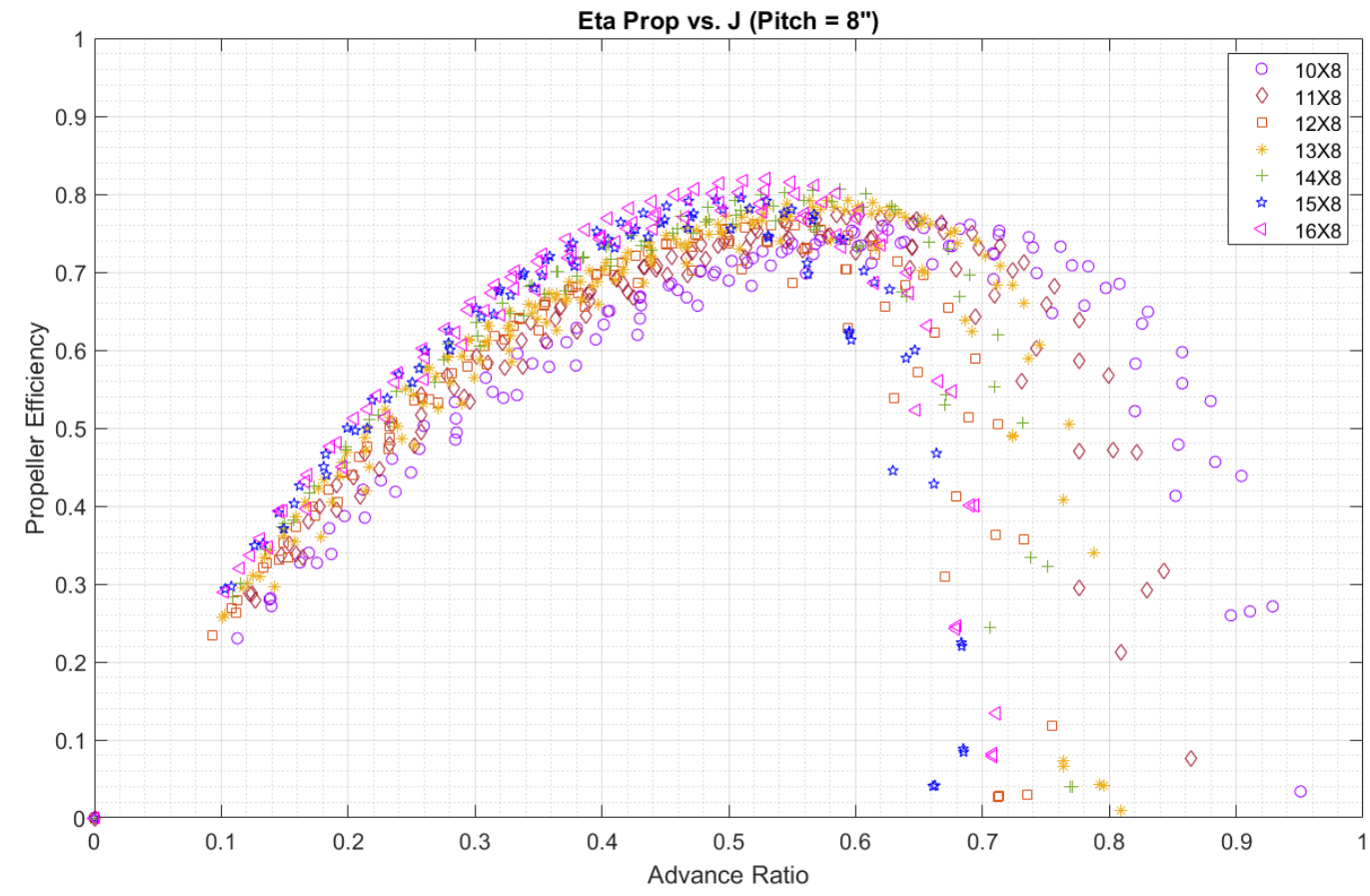

Figure 6: Propeller efficiency curve with 8-inch pitch for varying diameters. 


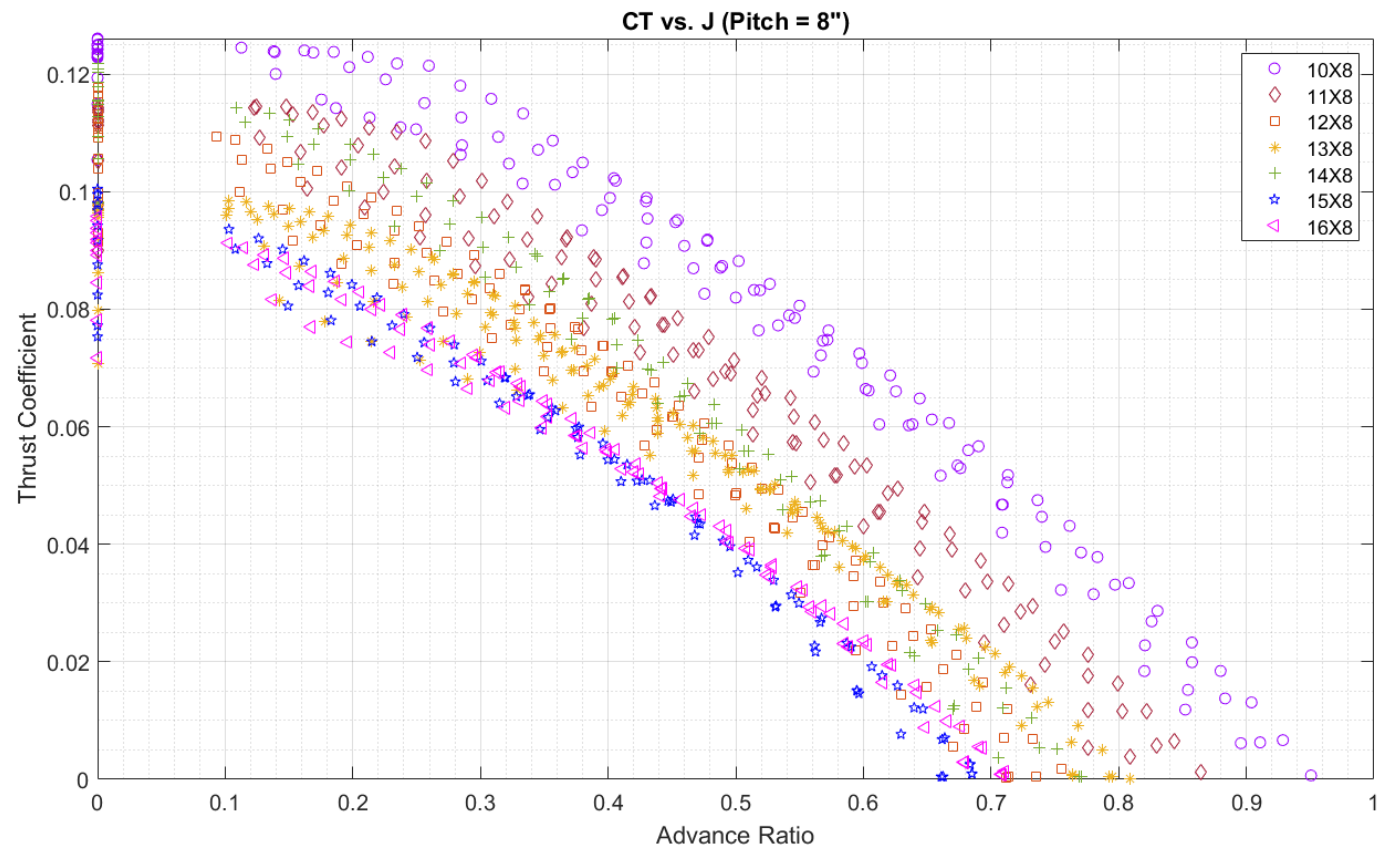

Figure 7: Thrust coefficient curves of propellers with 8-inch pitch for varying diameters.

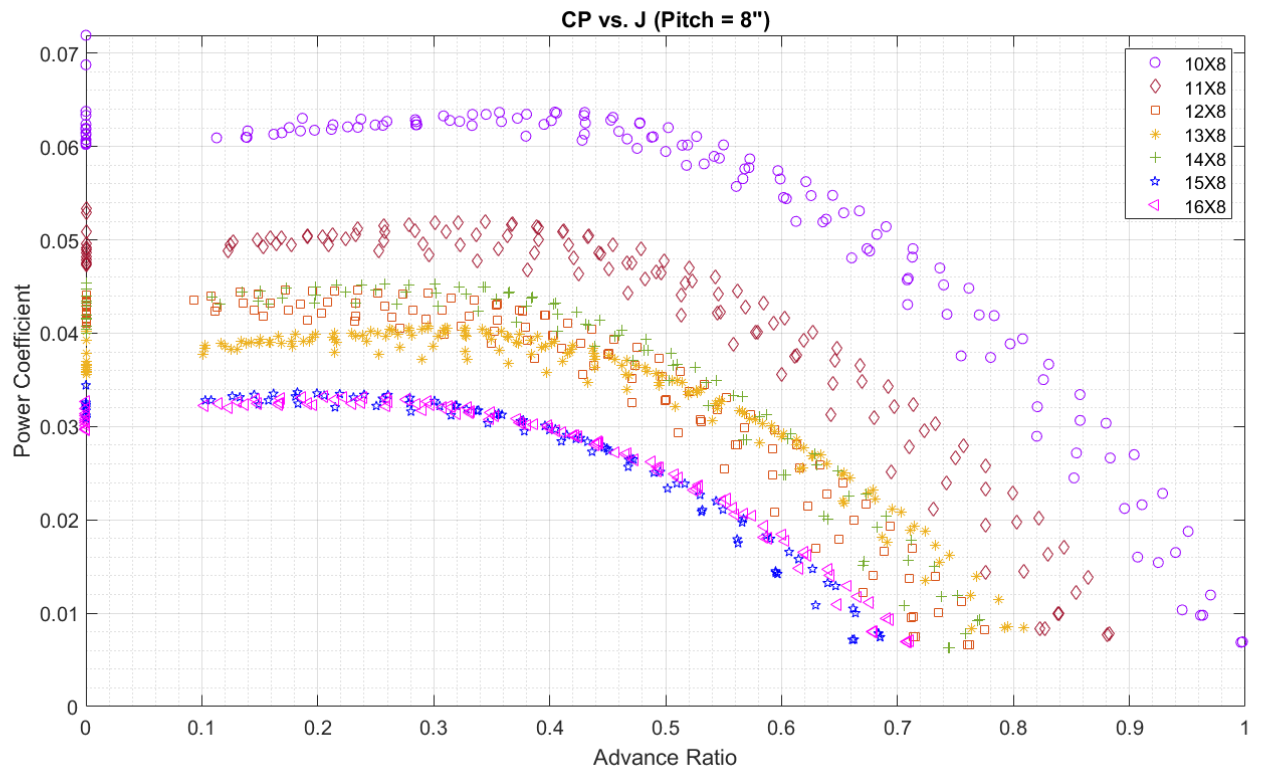

Figure 8: Power coefficient curves of propellers with 8-inch pitch for varying diameters.

Compared to the previous analysis, results of parametric analysis in relations to $\mathrm{P} / \mathrm{D}$ ratio showed greater degree of conformity for propeller efficiency and thrust and power coefficients, as shown in Fig. 9 through 11, respectively, with average P/D ratios provided in 
bracket for given plot colours. The degree of conformity varied depending on groups of similar P/D ratios, with propellers whose average P/D ratio of 0.846 showed the widest discrepancy of thrust and power coefficients. As mentioned, such discrepancies are in line with unique geometric profiles of each Aero-Naut propellers. For propeller efficiency curves based on Fig. 9, consistency in efficiency values were observed for groups of similar P/D ratios, and accurate propeller efficiency estimation is expected from this performance scaling relations. Therefore, it was determined that Aero-Naut CAM folding propeller performance can be estimated with good accuracy based on scaling relations using similar propeller $\mathrm{P} / \mathrm{D}$ ratios.

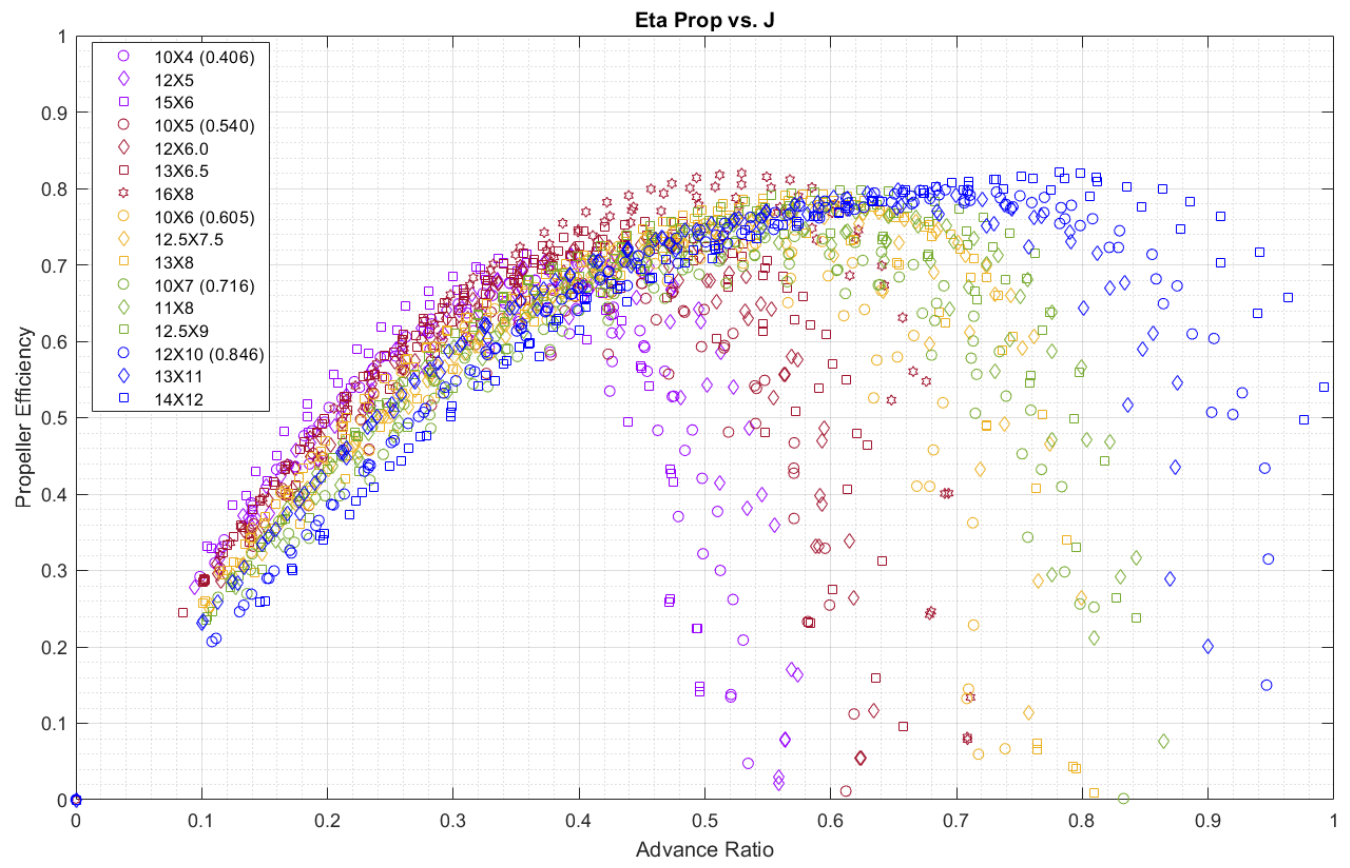

Figure 9: Propeller efficiency curves of propellers with varying P/D ratio. 
CT vs. J

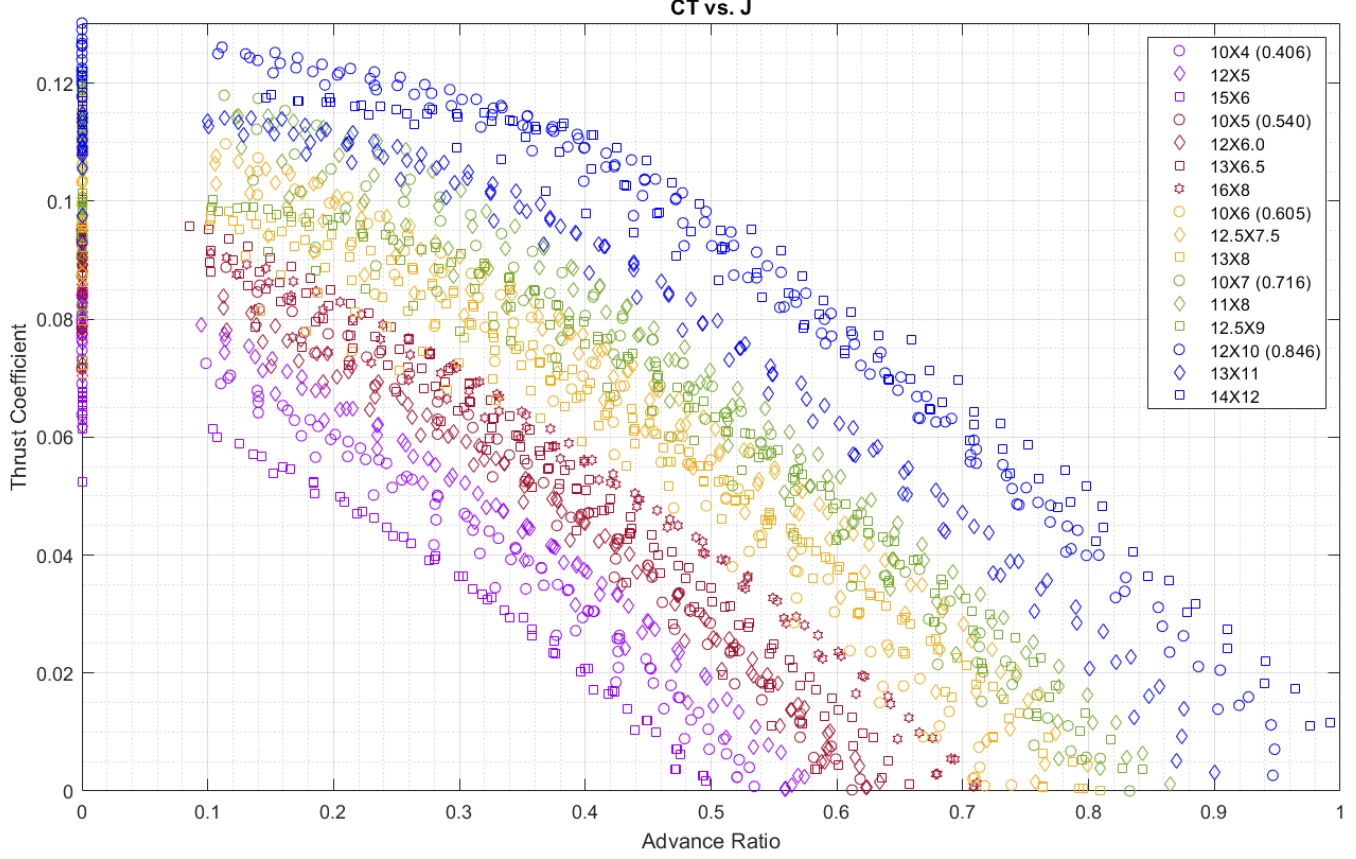

Figure 10: Thrust coefficient curves of propellers with varying P/D ratio.

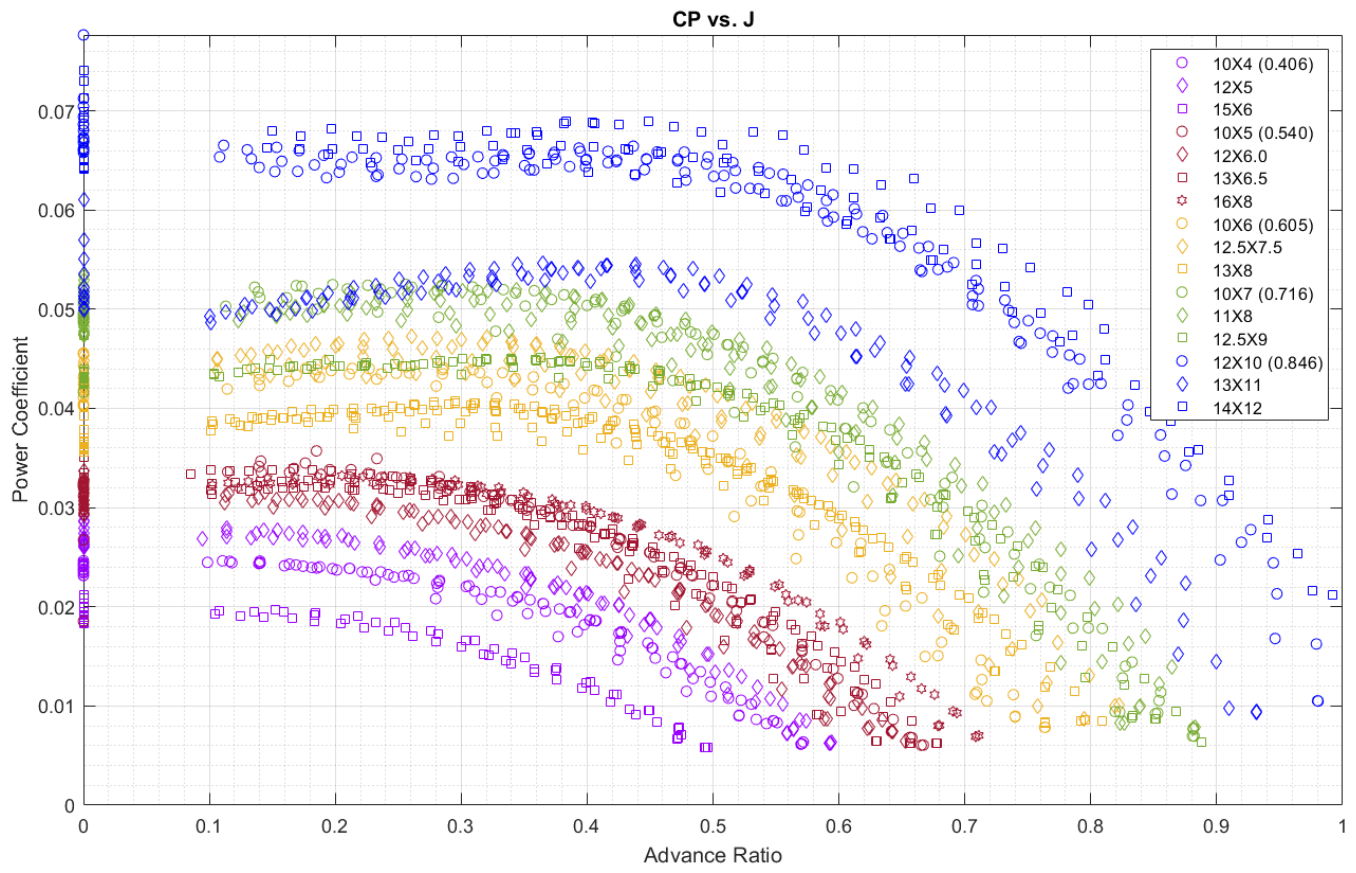

Figure 11: Power coefficient curves of propellers with varying P/D ratio. 
Performance prediction results for maximum attainable propeller and overall efficiencies for varying propeller geometry can be seen in Fig. 12 and 13, respectively. For the optimum operating condition of CREATeV, it was found that propellers with $\mathrm{P} / \mathrm{D}$ ratio of 0.846 had the highest propeller and overall theoretical efficiencies with values of 0.7919 and 0.6711 , respectively.

Several important analysis outcomes regarding efficiency optimization had been observed. Firstly, an increase of P/D ratio of 0.846 and thereafter did not result in greater performance gain but caused significant efficiency degradation. Secondly, an increase of propeller diameter did not guarantee an efficiency increase, and there existed the optimum propeller diameter for given $\mathrm{P} / \mathrm{D}$ ratio that provided maximum of maximum attainable overall efficiencies. Lists of theoretical optimum propellers and their operating conditions can be found in Table 3. Several Aero-Naut CAM folding propellers found in catalogues were recommended based on performance prediction results and can be found in Table 4. It should also be noted that due to lack of available propellers as P/D ratio increases, only one or two propellers analysis were available for P/D ratio greater than 0.8 , with the only exception being $\mathrm{P} / \mathrm{D}$ ratio of 0.846 . This however was not expected to severely affect the accuracy of propeller performance, as the performance scaling effect based on P/D ratio had been shown as per Fig. 9 through 11.

Although maximum of 3\% overall efficiency increase is anticipated when compared to current propellers, it is expected to enhance ultra-long-endurance capability of CREATeV and greatly benefit from its increased mission capability. Estimated thrust and power coefficient curve fit are presented in Appendix A, and performance graphs of propellers categorized by similar P/D ratios are presented in Appendix B. 


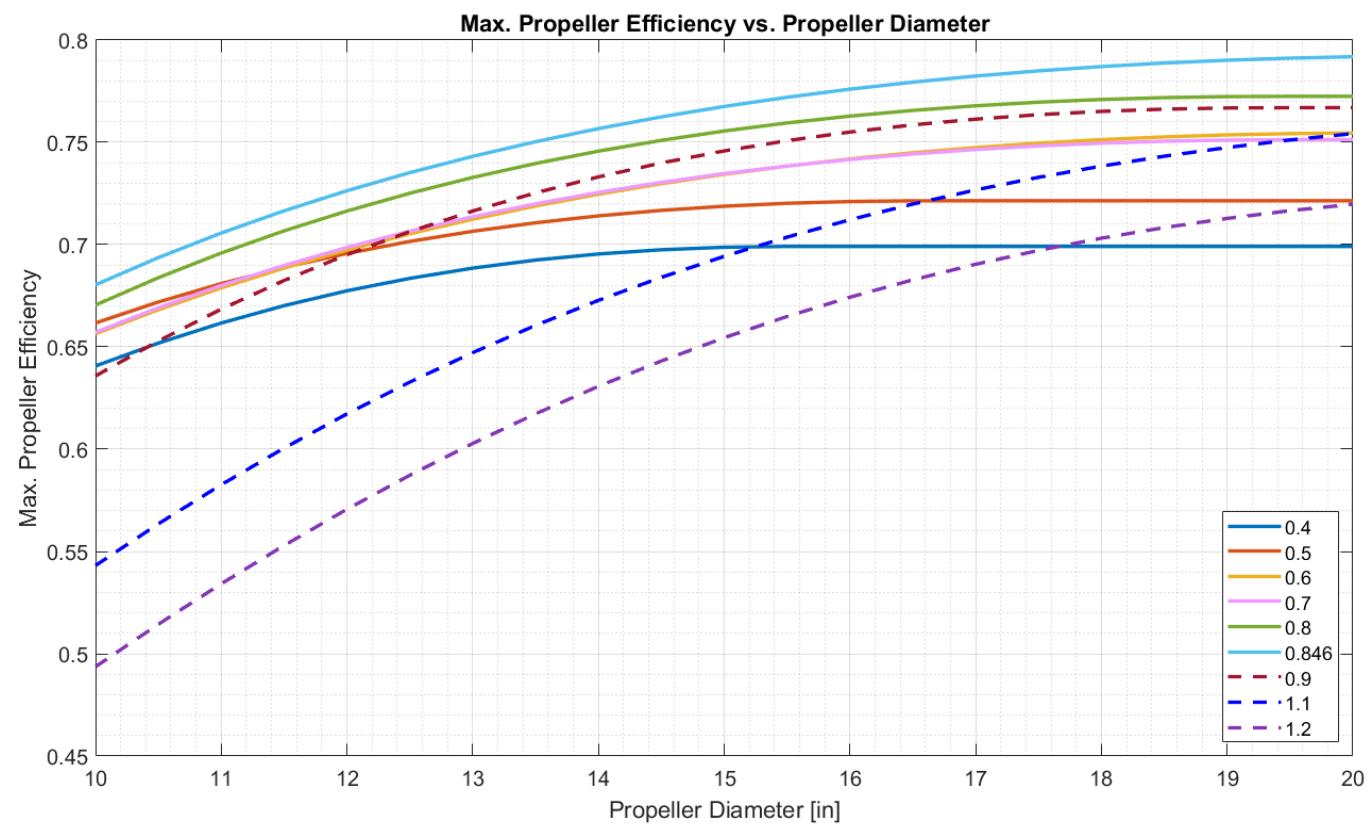

Figure 12: Estimated maximum propeller efficiency for varying propeller geometry.

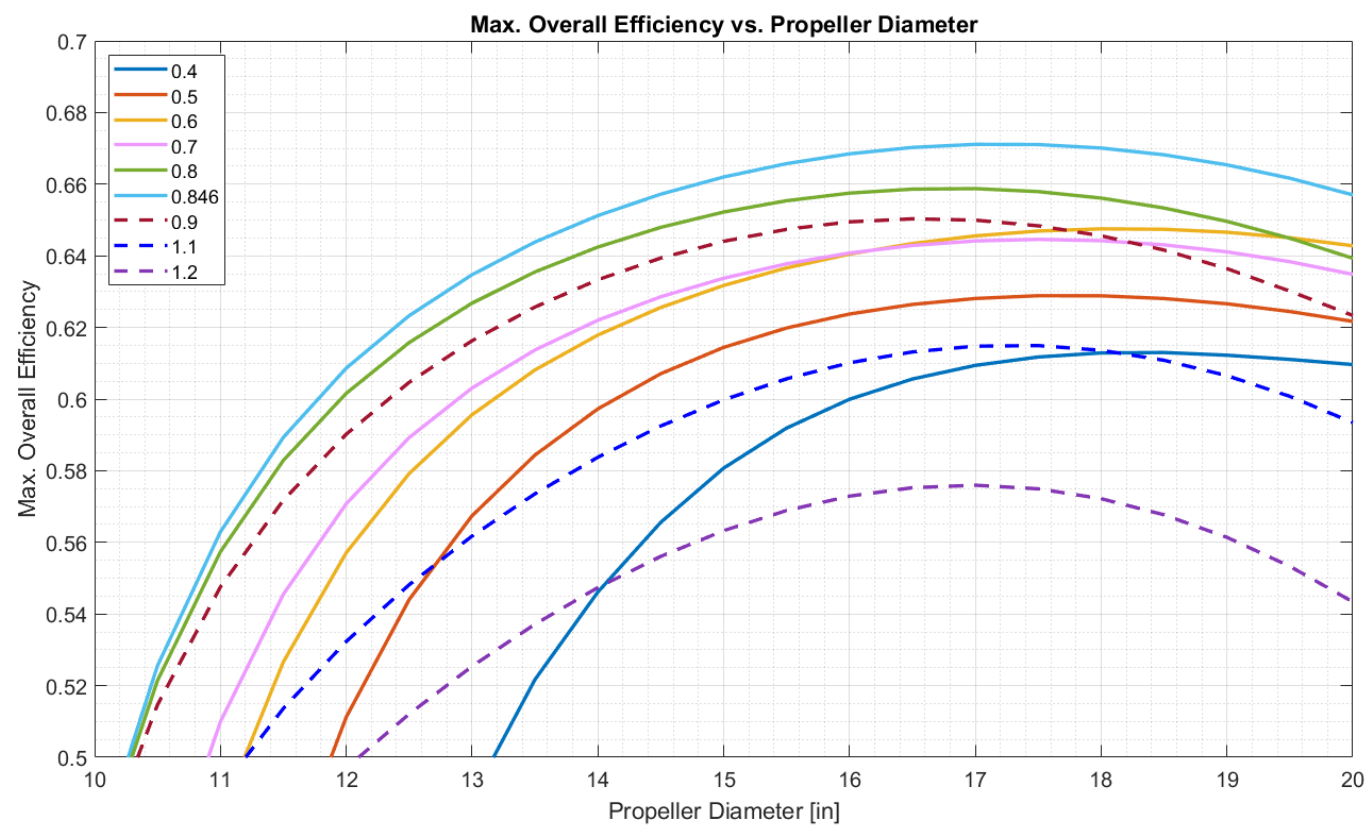

Figure 13: Estimated maximum overall efficiency for varying propeller geometry. 
Table 3: Theoretical Optimum Propellers for Maximum Efficiency

\begin{tabular}{|c|c|c|c|c|c|c|c|}
\hline P/D & $\begin{array}{c}\text { Diameter } \\
\text { [in] }\end{array}$ & Pitch [in] & $\begin{array}{c}\text { Max. } \\
\text { Overall } \\
\text { Efficiency }\end{array}$ & $\begin{array}{c}\text { Airspeed } \\
{[\mathbf{m} / \mathbf{s}]}\end{array}$ & $\begin{array}{c}\text { Thrust } \\
{[\mathbf{N}]}\end{array}$ & $\begin{array}{c}\text { Power } \\
\text { In [W] }\end{array}$ & $\begin{array}{c}\text { Torque } \\
{[\mathbf{N} * \mathbf{m}]}\end{array}$ \\
\hline 0.4 & 18.50 & 7.40 & 0.6130 & 11.0 & 7.0 & 125.51 & 0.276 \\
\hline 0.5 & 17.50 & 8.75 & 0.6289 & 11.0 & 6.4 & 111.87 & 0.271 \\
\hline 0.6 & 18.00 & 10.80 & 0.6475 & 11.0 & 5.0 & 84.88 & 0.258 \\
\hline 0.7 & 17.50 & 12.25 & 0.6446 & 11.0 & 5.0 & 85.27 & 0.262 \\
\hline 0.8 & 17.00 & 13.60 & 0.6588 & 11.0 & 5.0 & 83.43 & 0.274 \\
\hline $\mathbf{0 . 8 4 6}$ & $\mathbf{1 7 . 0 0}$ & $\mathbf{1 4 . 3 8}$ & $\mathbf{0 . 6 7 1 1}$ & $\mathbf{1 1 . 0}$ & $\mathbf{5 . 0}$ & $\mathbf{8 1 . 8 9}$ & $\mathbf{0 . 2 6 9}$ \\
\hline 0.9 & 16.50 & 14.85 & 0.6503 & 11.0 & 5.0 & 84.51 & 0.280 \\
\hline 1.1 & 17.50 & 19.25 & 0.61493 & 11.0 & 5.0 & 89.37 & 0.338 \\
\hline 1.2 & 17.00 & 20.40 & 0.57595 & 11.0 & 5.0 & 95.42 & 0.359 \\
\hline
\end{tabular}

Table 4: Recommended Aero-Naut CAM propellers for CREATeV

\begin{tabular}{|c|c|c|c|}
\hline Propeller & P/D & Estimated Overall Efficiency & Note \\
\hline $18 \times 9$ & 0.50 & 0.6288 & \multirow{2}{*}{ Current } \\
\hline $20 \times 10$ & 0.50 & 0.6217 & \\
\hline $16 X 13$ & 0.81 & 0.6575 & \multirow{6}{*}{ Recommended } \\
\hline $14 \times 12$ & 0.86 & 0.6512 & \\
\hline $18 \times 11$ & 0.61 & 0.6475 & \\
\hline $17 X 11$ & 0.65 & 0.6456 & \\
\hline $15 \times 13$ & 0.87 & 0.6440 & \\
\hline $13 \times 11$ & 0.85 & 0.6347 & \\
\hline
\end{tabular}




\section{Chapter 5. Conclusion}

This report investigated performance prediction method for Aero-Naut CAM folding propellers through parametric studies of existing wind tunnel testing data. The main objective was to optimize propeller selection of CREATeV using the estimated performance scaling relations of the propeller geometry determined from parametric studies. Due to the unique geometric profiles of every Aero-Naut folding propellers, it was proven to be challenging in determining proper performance scaling effect through parametric studies. Nevertheless, it was found that scaling relations in relations to propeller P/D ratio provided relatively accurate performance estimates, especially the propeller efficiency. Further analysis into the efficiency at CREATeV's operating condition showed optimized P/D ratio of 0.846 with theoretical optimum propeller diameter of 17 inches. Compared to the current selection of 18X9 Aero-Naut CAM propeller, the efficiency increase is estimated to be about $4 \%$. When selecting the existing model of $16 \times 13$, the efficiency increase is about $3 \%$. While the magnitude of efficiency increase is marginal, the benefit towards ultra-long-endurance mission requirement of CREATeV is expected to be significant.

For future work, the estimated propeller performance prediction would be validated through wind tunnel testing conducted at RAALF. While it was the original intention of the author to obtain such test data during the thesis research, the author regrets to recall that coronavirus restrictions along with logistical issues for shipment of propellers made such endeavour impossible. Further works may include in-depth measurements of Aero-Naut CAM propellers of interests for geometric characteristics such as propeller twist angle. Finally, performance results during full-scale testing of CREATeV may provide realistic impact on performance prediction results presented in this paper. 


\section{References}

[1] CREATeV, “CREATeV - Clean Renewable Energy Aerial Test Vehicle," http://createv.ca/, Accessed February 2021.

[2] Dantsker, O. D., Theile, M., Caccamo, M., and Mancuso, R., "Design, Development, and Initial Testing of a Computationally-Intensive, Long-Endurance Solar-Powered Unmanned Aircraft," AIAA 2018-4217, AIAA AVIATION 2018 Applied Aerodynamics Conference, June 2018.

\section{https://doi.org/10.2514/6.2018-4217}

[3] RAALF, "CREATeV flies for over 10 hours using solar power," https://ralf.blog.ryerson.ca/2020/11/14/createv-flies-for-over-10-hours-using-solarpower/, Accessed February 2021.

[4] Dantsker, O. D., Caccamo, M., Deters, R. W., and Selig, M. S., "Performance Testing of AeroNaut CAM Folding Propellers", AIAA 2020-2762, AIAA AVIATION 2020 Forum, June 2020. https://doi.org/10.2514/6.2020-2762

[5] Jessa, A., "Low Reynolds Number Scaling Effects for Small-Scale Rotors", Master's Thesis, Department of Aerospace Engineering, Ryerson Univ., Toronto, ON, 2018.

[6] Esprit Tech, "Aeronaut CAM Folding Propellers (Rudi Freudenthaler)," https://www.espritmodel.com/aeronaut-cam-folding-propellers-rudi-freudenthaler.aspx, Accessed February 2021.

[7] Gudmundsson, S., General Aviation Aircraft Design, Butterworth-Heinemann, Oxford, U.K., 2013.

[8] McDougall, T. J., and Wotherspoon, S. J., "A Simple Modification of Newton's Method to Achieve Convergence of Order $1+\sqrt{2}$ ", Applied Mathematics Letter, Vol. 29, March 2014, pp. 20-25.

https://doi.org/10.1016/j.aml.2013.10.008 


\section{Appendix A: Thrust and Power Coefficient Curve Fit Equations}

Table 5: Thrust Coefficient Curve Fit

\begin{tabular}{|c|c|c|c|c|c|}
\hline $\boldsymbol{P} / \boldsymbol{D}$ & $\boldsymbol{J}^{\wedge} \mathbf{4}$ & $\boldsymbol{J}^{\wedge} \mathbf{3}$ & $\boldsymbol{J}^{\wedge} \mathbf{2}$ & $\boldsymbol{J}^{\wedge} \mathbf{1}$ & $\boldsymbol{J}^{\wedge} \boldsymbol{~}$ \\
\hline 0.4 & 0 & 0 & -0.14983 & -0.054303 & 0.07109 \\
\hline 0.5 & 0.37088 & -0.24697 & -0.18112 & -0.012922 & 0.089465 \\
\hline 0.6 & 0.038813 & 0.047003 & -0.22146 & -0.0023939 & 0.10244 \\
\hline 0.7 & -0.059949 & 0.19932 & -0.31751 & 0.035951 & 0.10529 \\
\hline 0.8 & -0.028618 & 0.11393 & -0.25837 & 0.03821 & 0.12317 \\
\hline 0.846 & 0.16675 & -0.23377 & -0.06775 & 0.018489 & 0.11642 \\
\hline 0.9 & 0.064315 & -0.088104 & -0.12338 & 0.049222 & 0.11318 \\
\hline 1.1 & 0.030028 & -0.065221 & -0.05336 & 0.027383 & 0.11088 \\
\hline 1.2 & 0.02877 & -0.083157 & -0.01755 & 0.012643 & 0.12311 \\
\hline
\end{tabular}

Table 6: Power Coefficient Curve Fit

\begin{tabular}{|c|c|c|c|c|c|}
\hline $\boldsymbol{P} \boldsymbol{D}$ & $\boldsymbol{J}^{\wedge} \mathbf{4}$ & $\boldsymbol{J}^{\wedge} \mathbf{3}$ & $\boldsymbol{J}^{\wedge} \mathbf{2}$ & $\boldsymbol{J}^{\wedge} \mathbf{1}$ & $\boldsymbol{J}^{\wedge} \mathbf{0}$ \\
\hline 0.4 & 0 & 0 & -0.07455 & 0.012779 & 0.021614 \\
\hline 0.5 & 0.36445 & -0.50468 & 0.12411 & -0.0009428 & 0.031086 \\
\hline 0.6 & 0.26034 & -0.47695 & 0.17948 & -0.01124 & 0.040615 \\
\hline 0.7 & 0.17366 & -0.38644 & 0.17272 & -0.017396 & 0.047451 \\
\hline 0.8 & 0.10582 & -0.32698 & 0.20331 & -0.039973 & 0.065716 \\
\hline 0.846 & 0.3197 & -0.74291 & 0.46398 & -0.089692 & 0.063017 \\
\hline 0.9 & 0.038895 & -0.20945 & 0.18222 & -0.056889 & 0.079119 \\
\hline 1.1 & 0.02269 & -0.16808 & 0.21313 & -0.10606 & 0.10678 \\
\hline 1.2 & -0.036068 & 0.008914 & 0.058793 & -0.073273 & 0.13281 \\
\hline
\end{tabular}




\section{Appendix B: Performance Graphs of Analyzed Propellers}

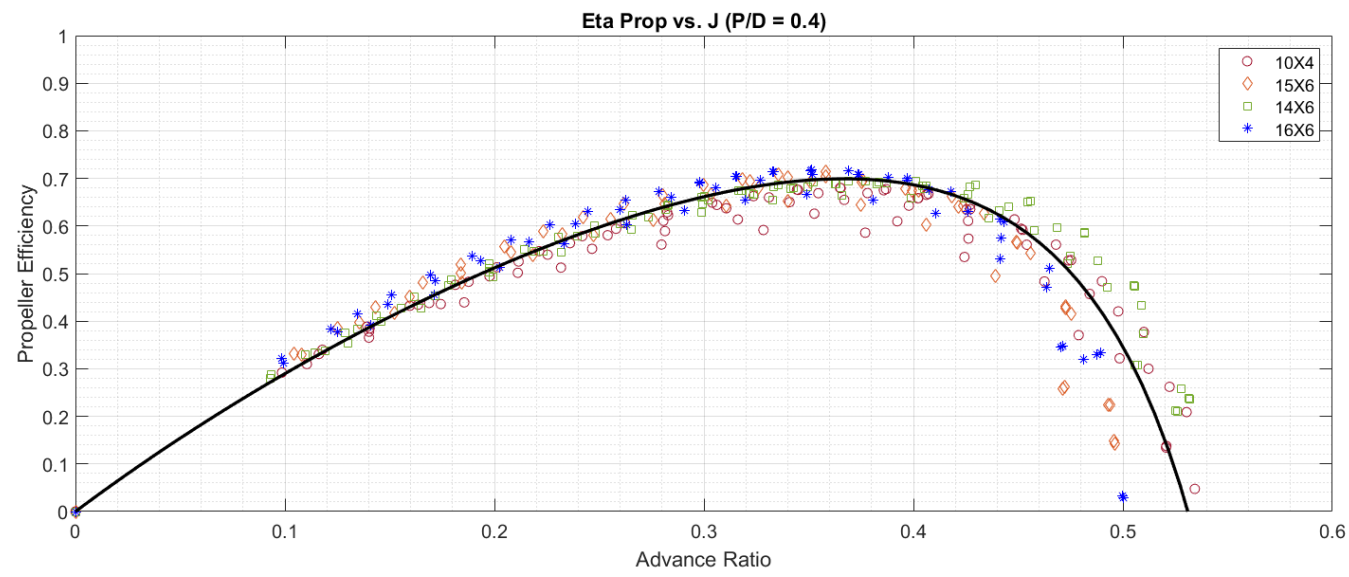

(a)

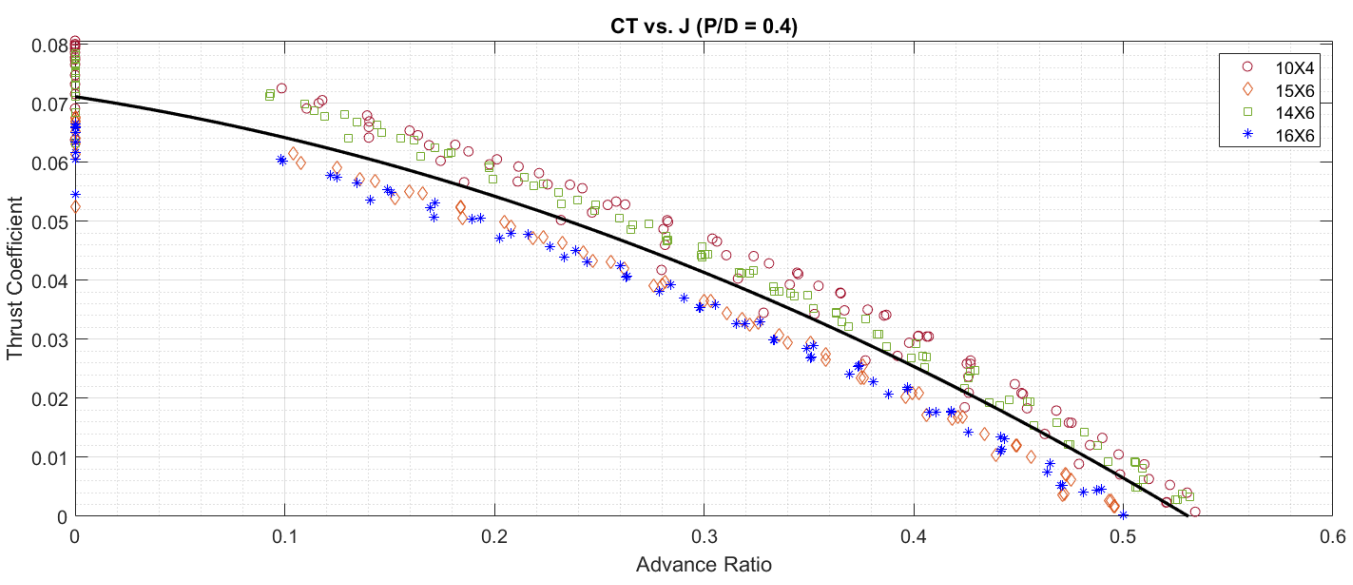

(b)

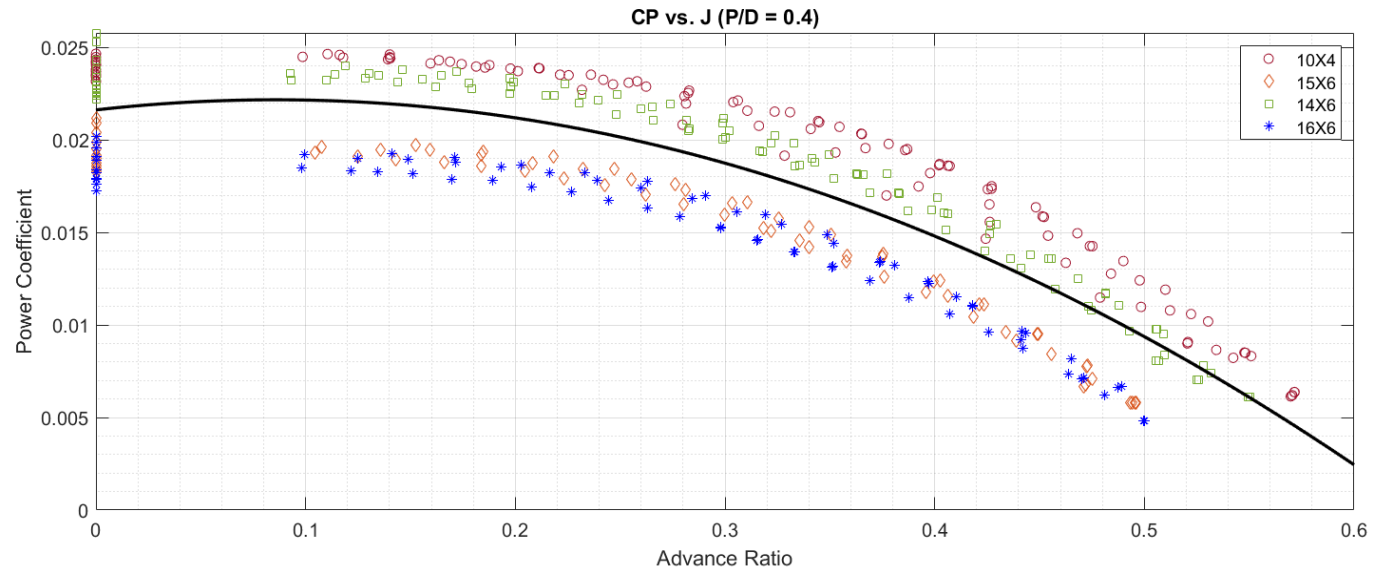

(c)

Figure 14: (a) propeller efficiency, (b) thrust coefficient, and (c) power coefficient of propeller with $\mathrm{P} / \mathrm{D}=0.4$. 


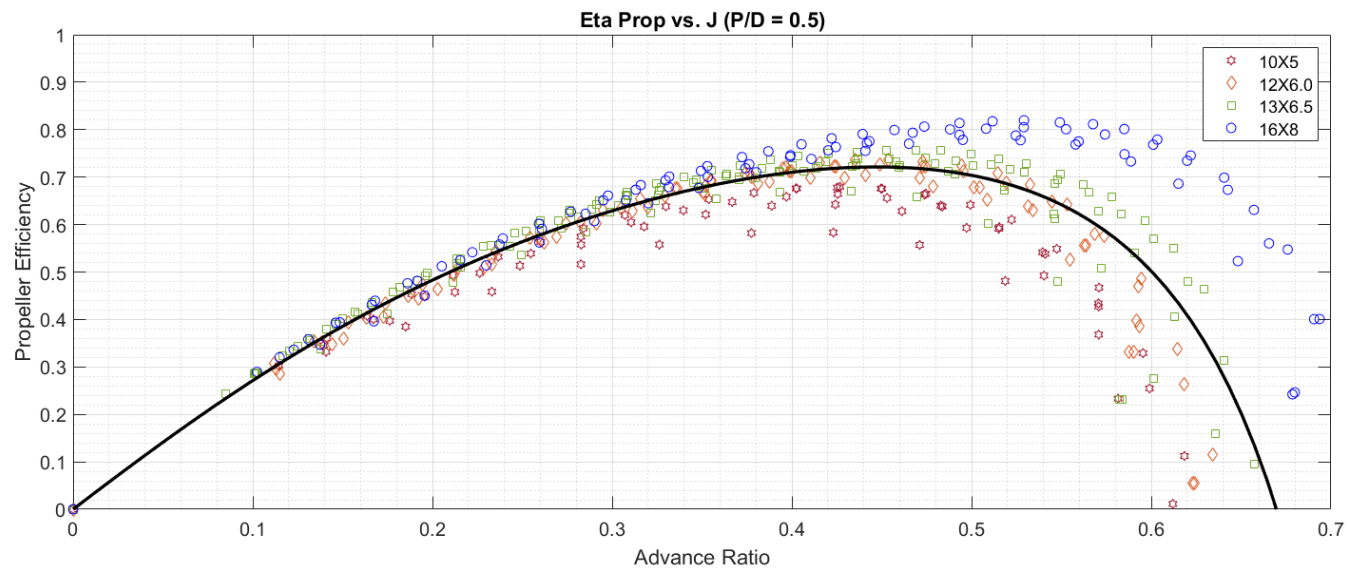

(a)

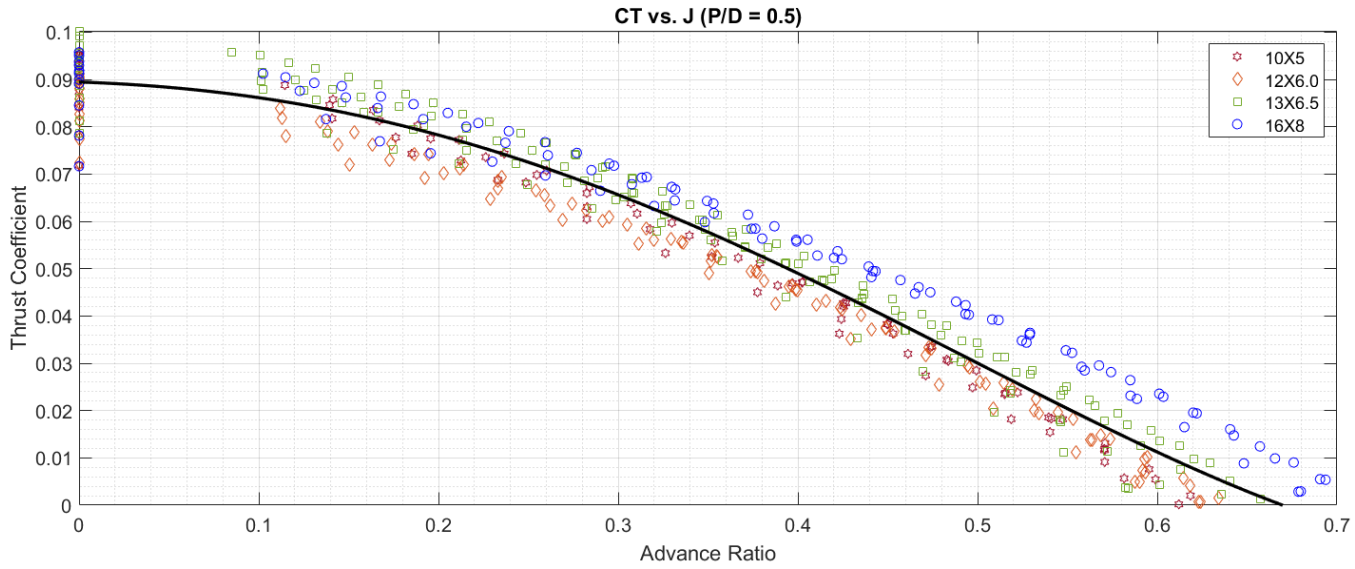

(b)

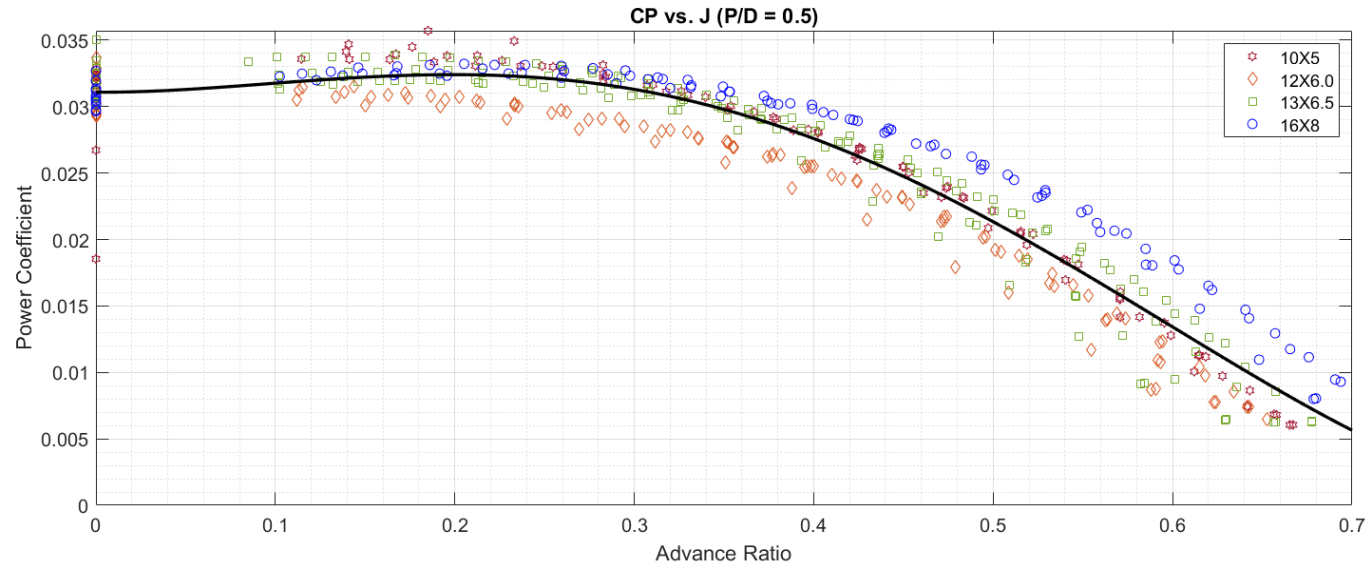

(c)

Figure 15: (a) propeller efficiency, (b) thrust coefficient, and (c) power coefficient of propeller with P/D = 0.5. 


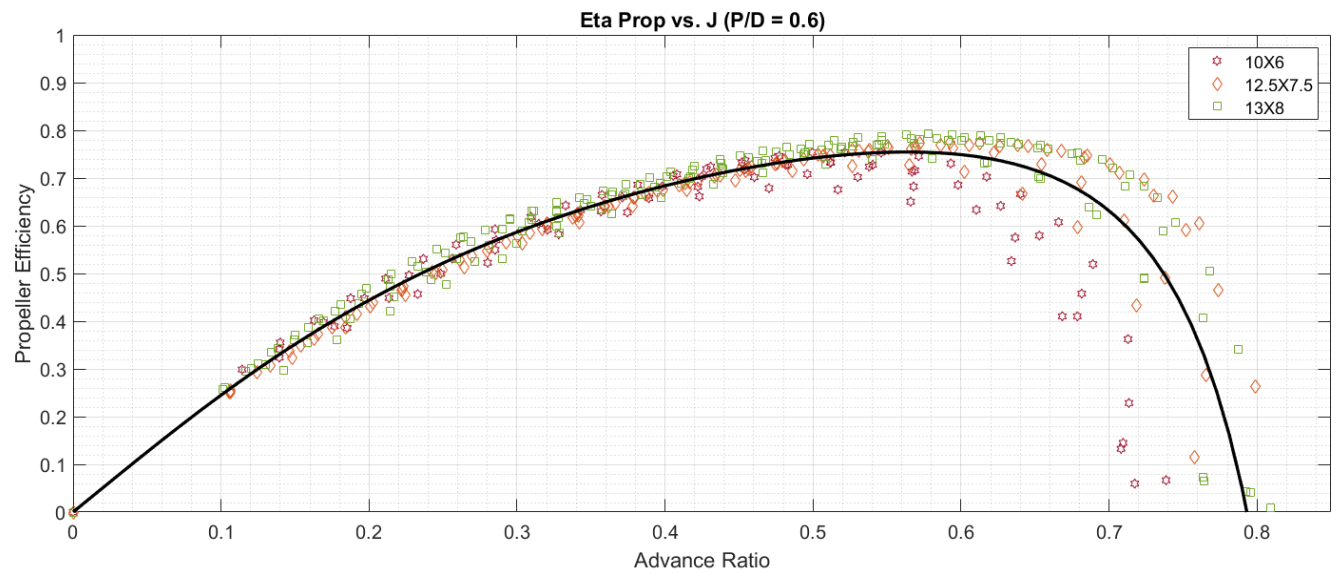

(a)

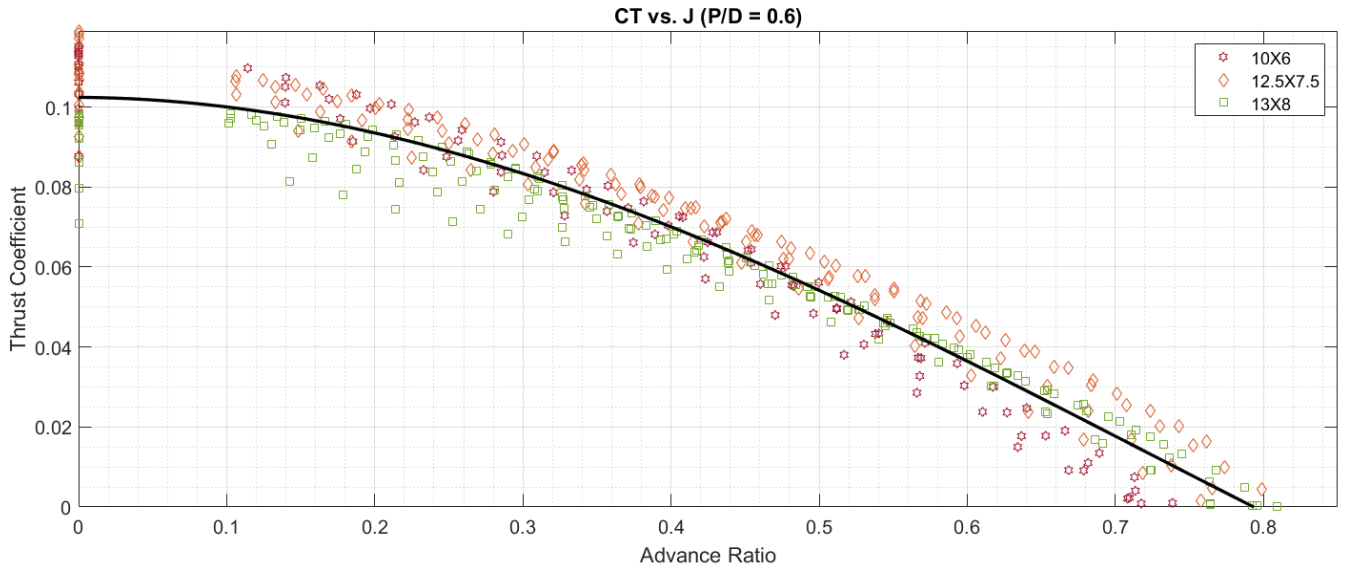

(b)

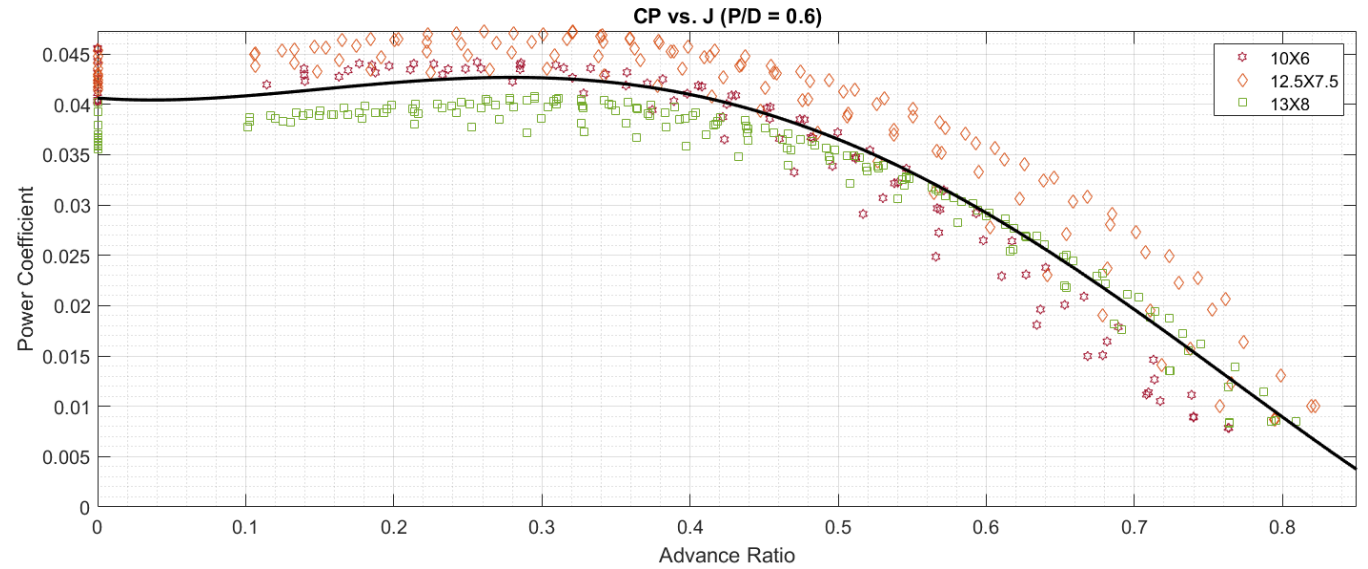

(c)

Figure 16: (a) propeller efficiency, (b) thrust coefficient, and (c) power coefficient of propeller with P/D = 0.6. 


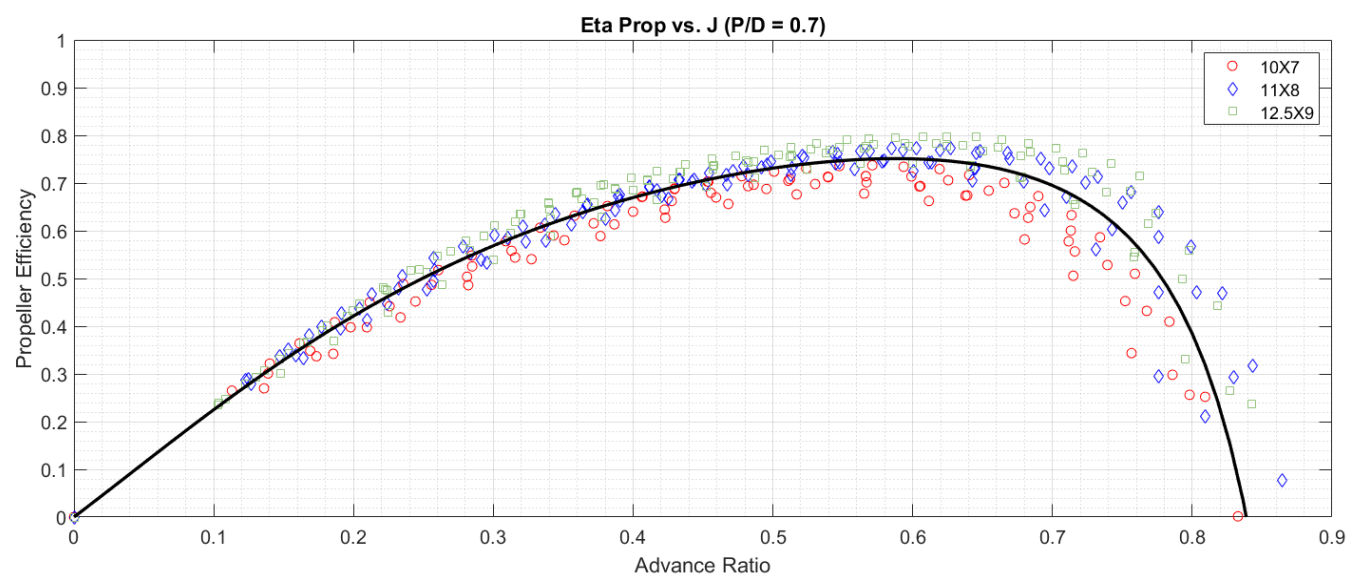

(a)

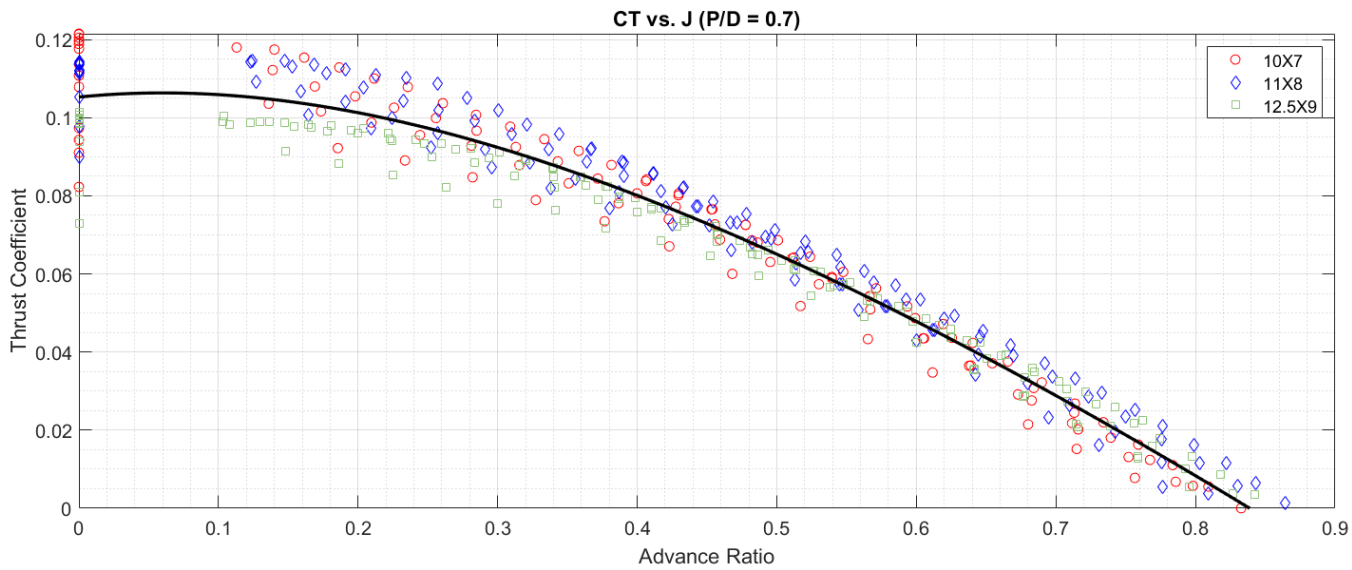

(b)

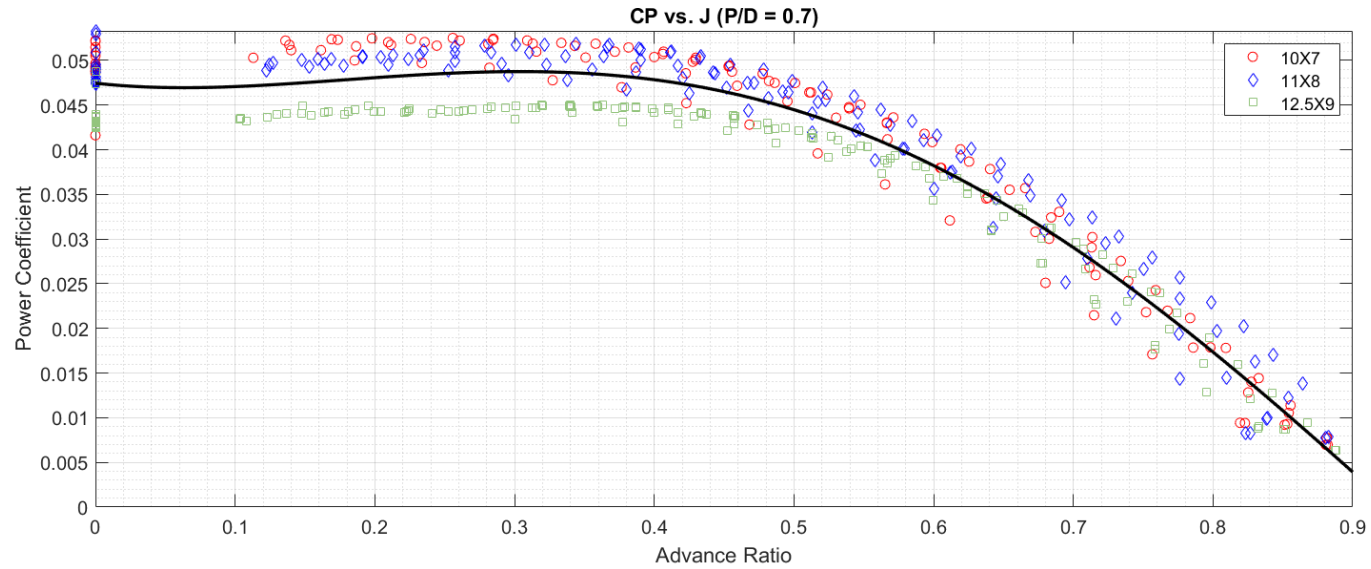

(c)

Figure 17: (a) propeller efficiency, (b) thrust coefficient, and (c) power coefficient of propeller with P/D = 0.7. 


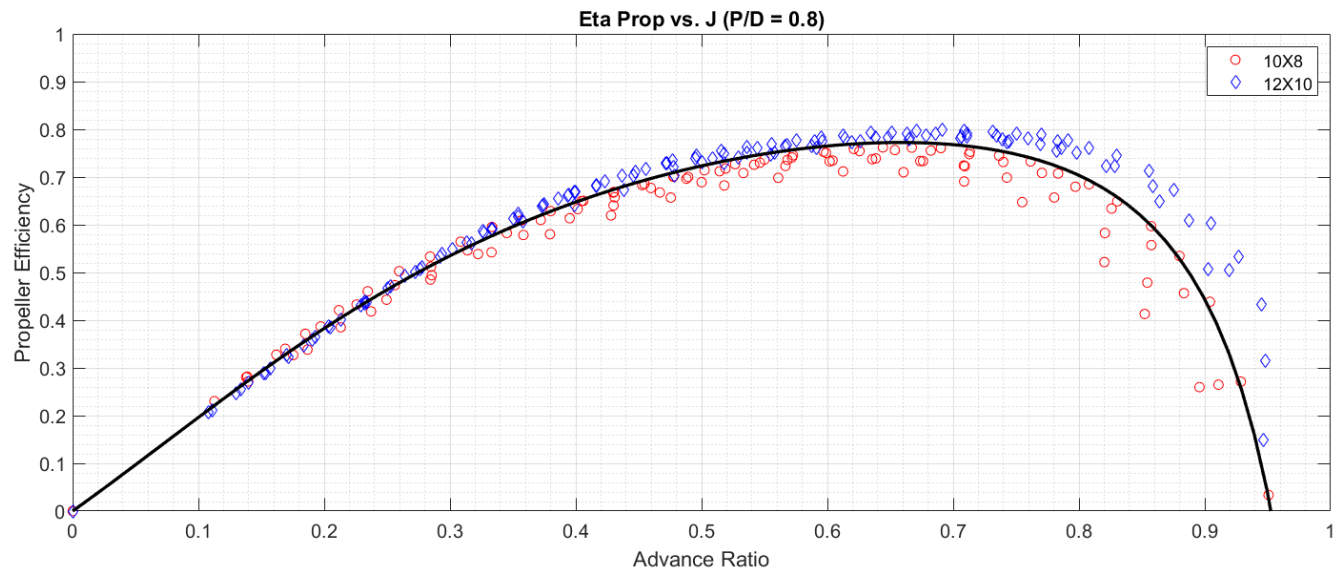

(a)

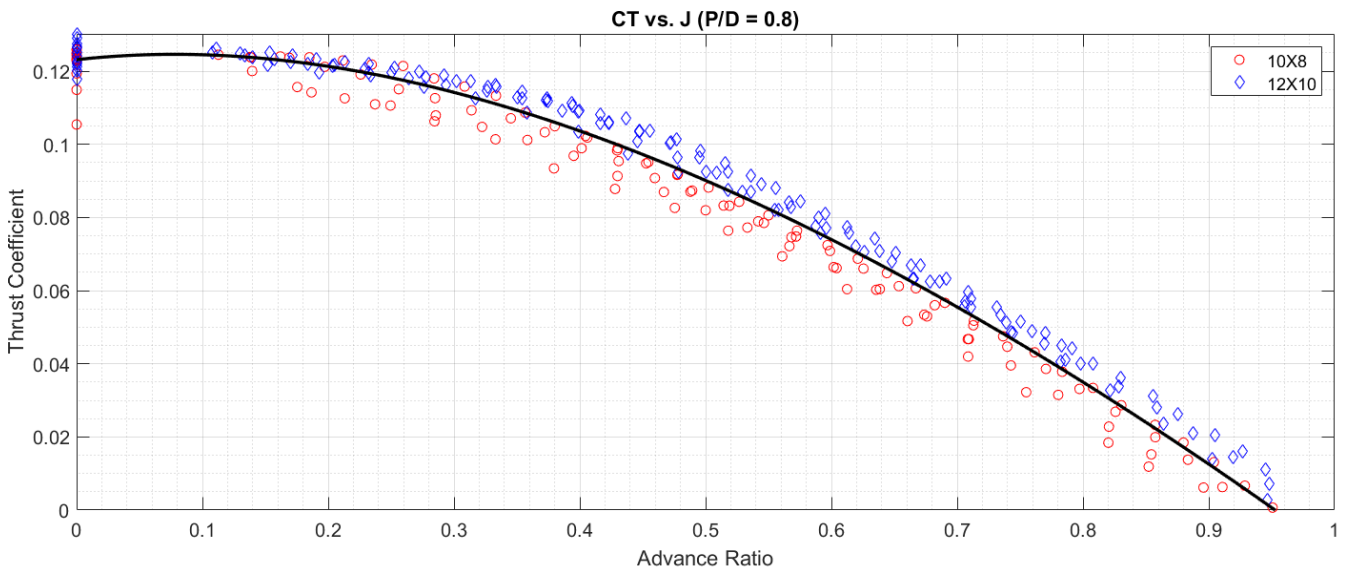

(b)

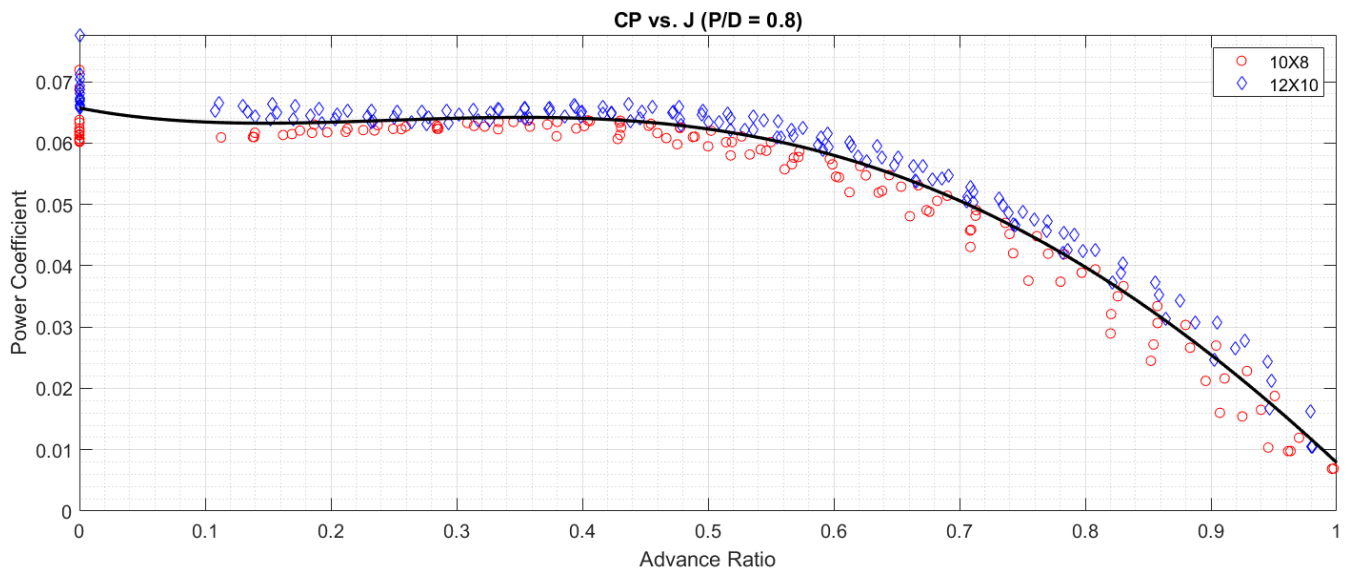

(c)

Figure 18: (a) propeller efficiency, (b) thrust coefficient, and (c) power coefficient of propeller with P/D $=0.8$. 


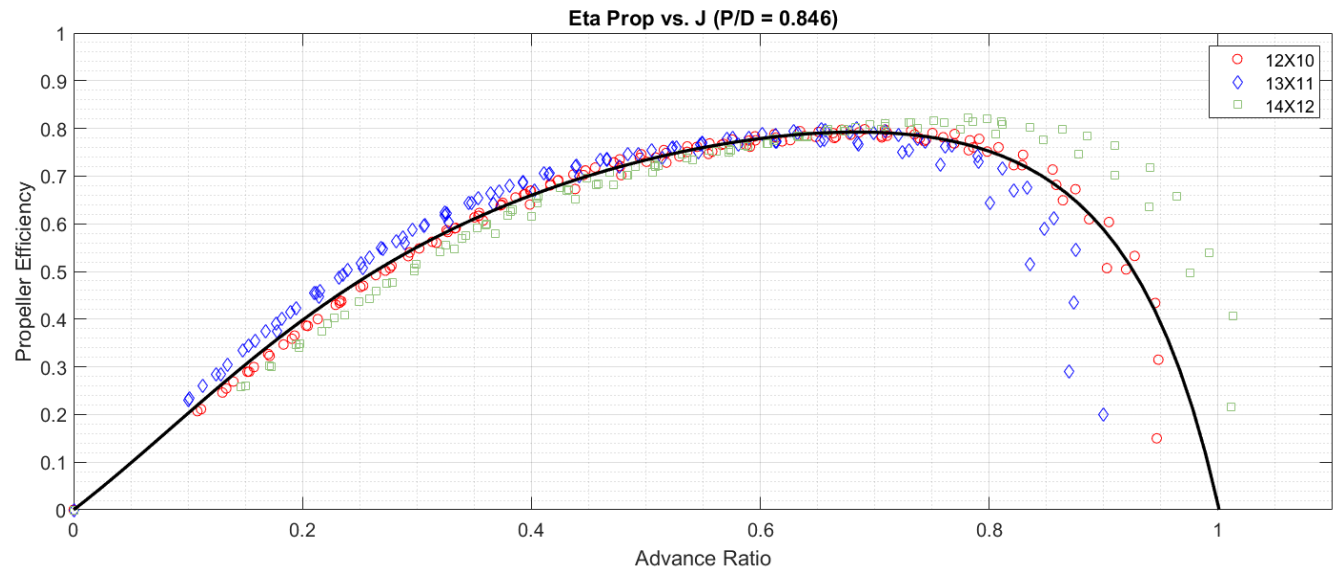

(a)

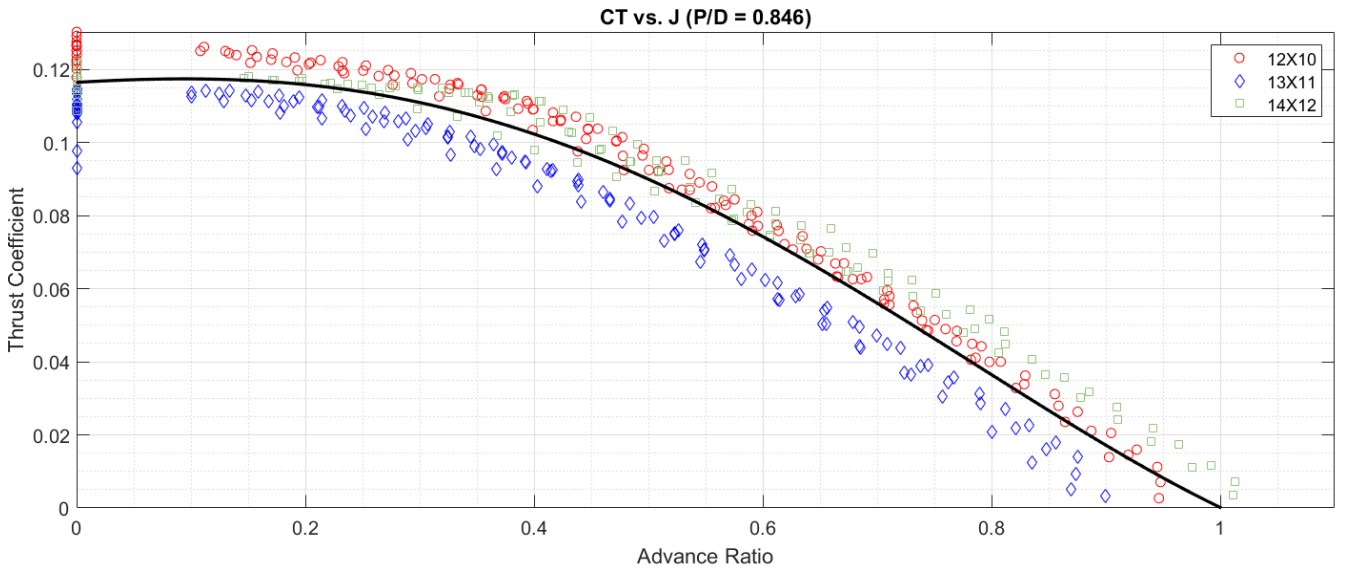

(b)

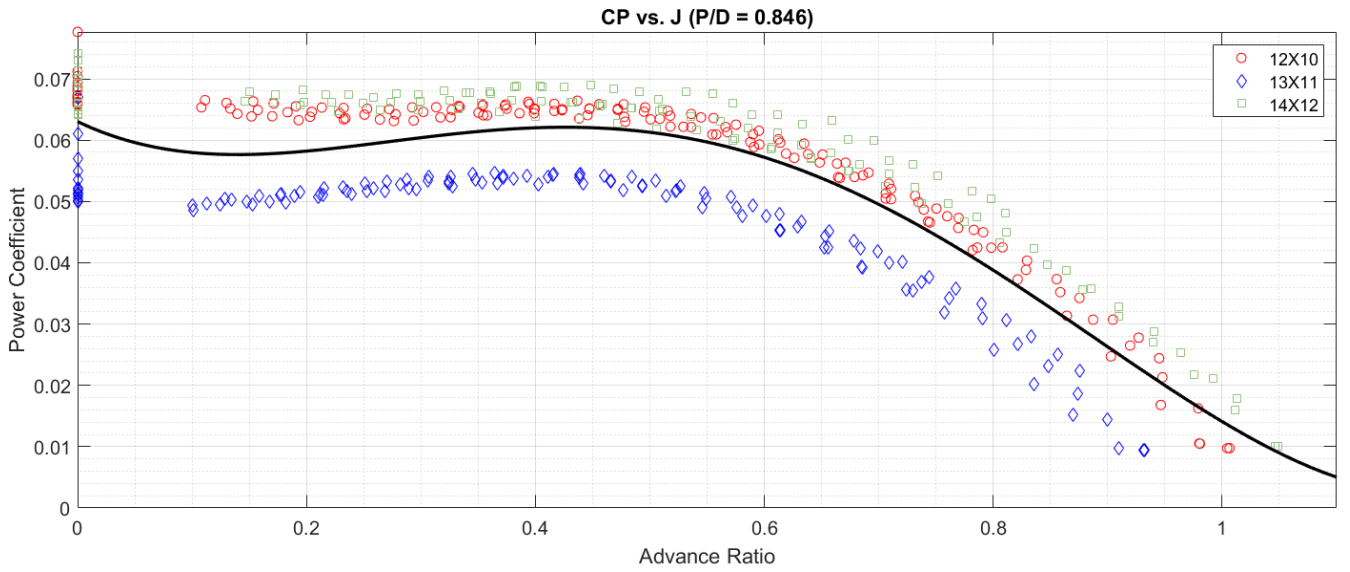

(c)

Figure 19: (a) propeller efficiency, (b) thrust coefficient, and (c) power coefficient of propeller with $\mathrm{P} / \mathrm{D}=0.846$. 


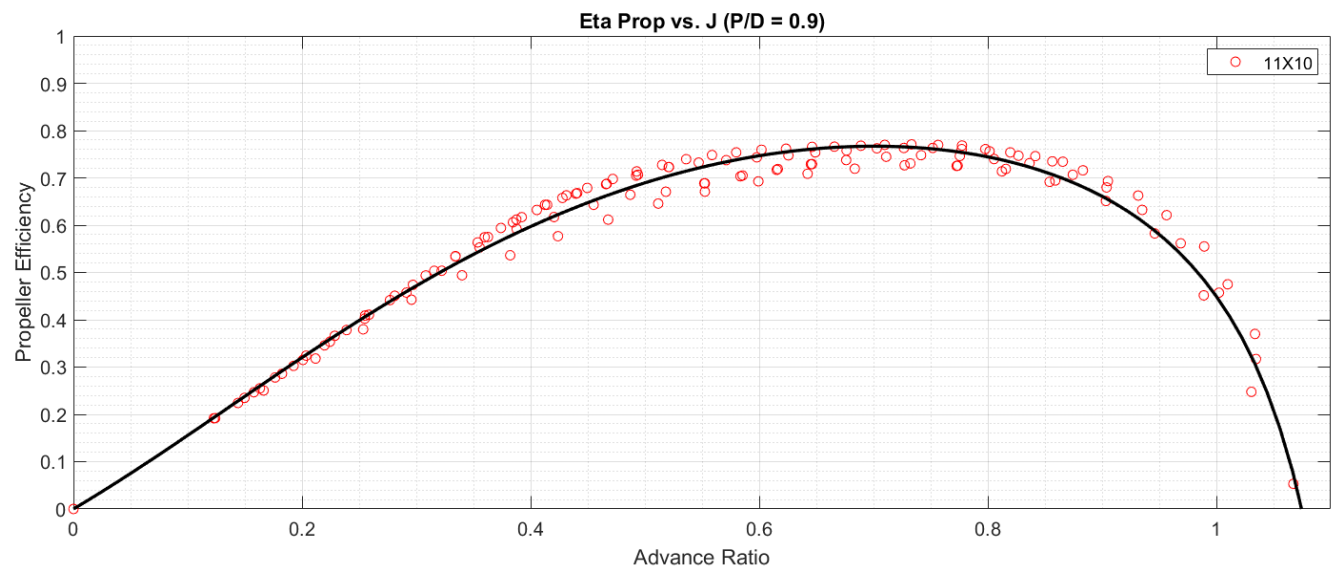

(a)

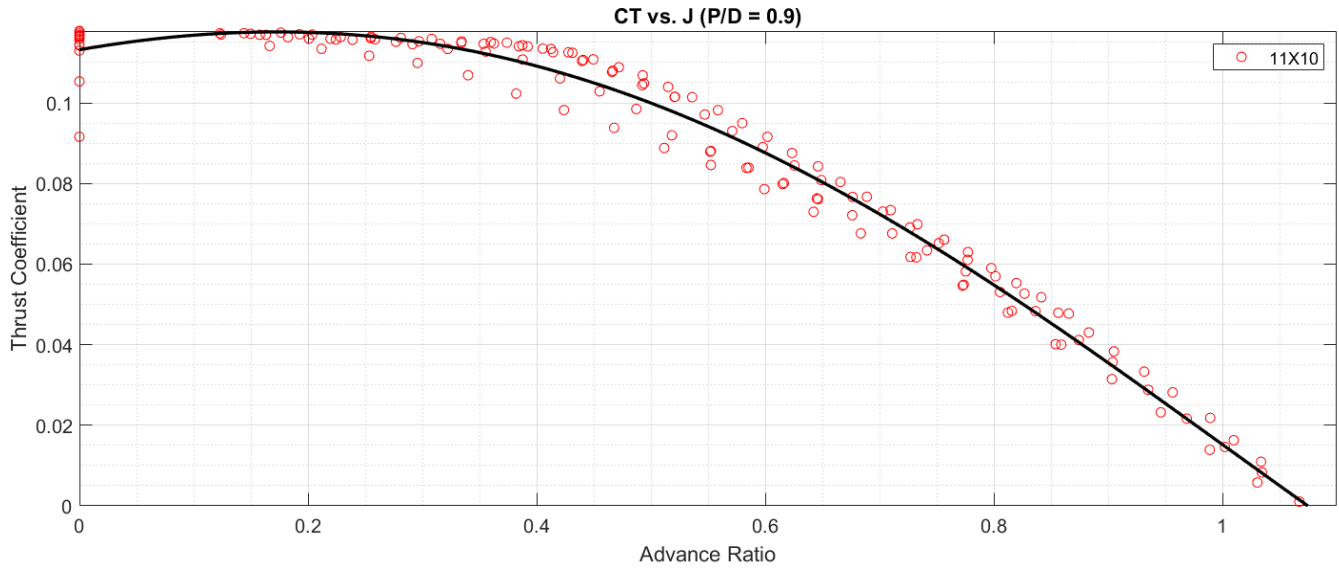

(b)

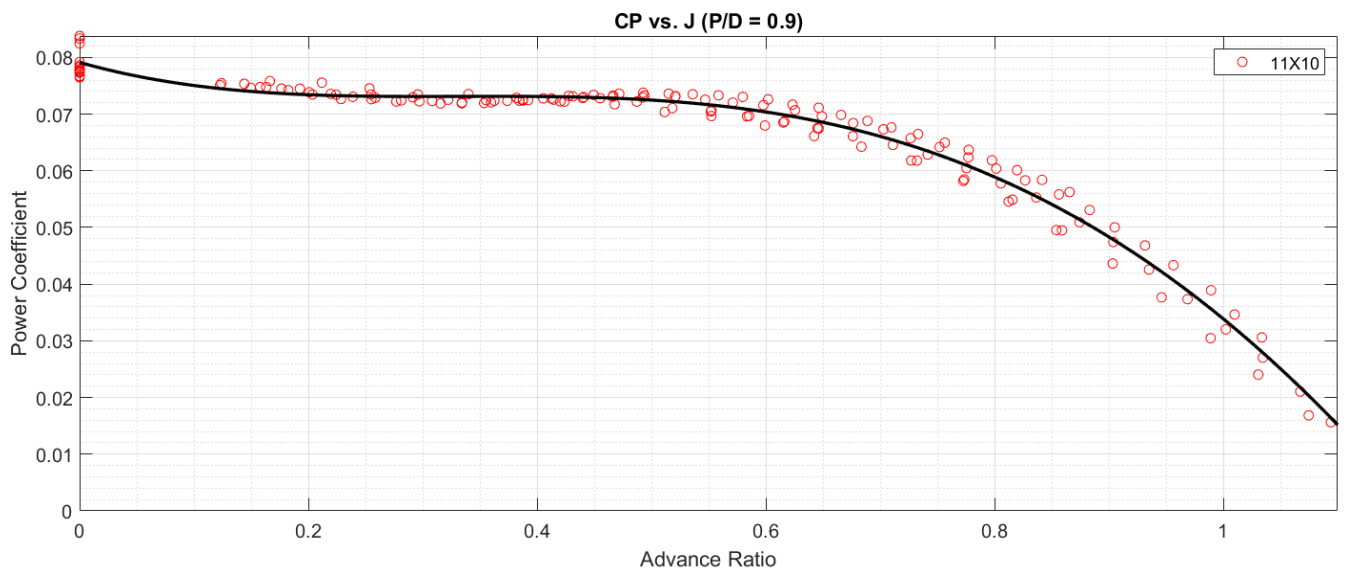

(c)

Figure 20: (a) propeller efficiency, (b) thrust coefficient, and (c) power coefficient of propeller with $\mathrm{P} / \mathrm{D}=0.9$. 


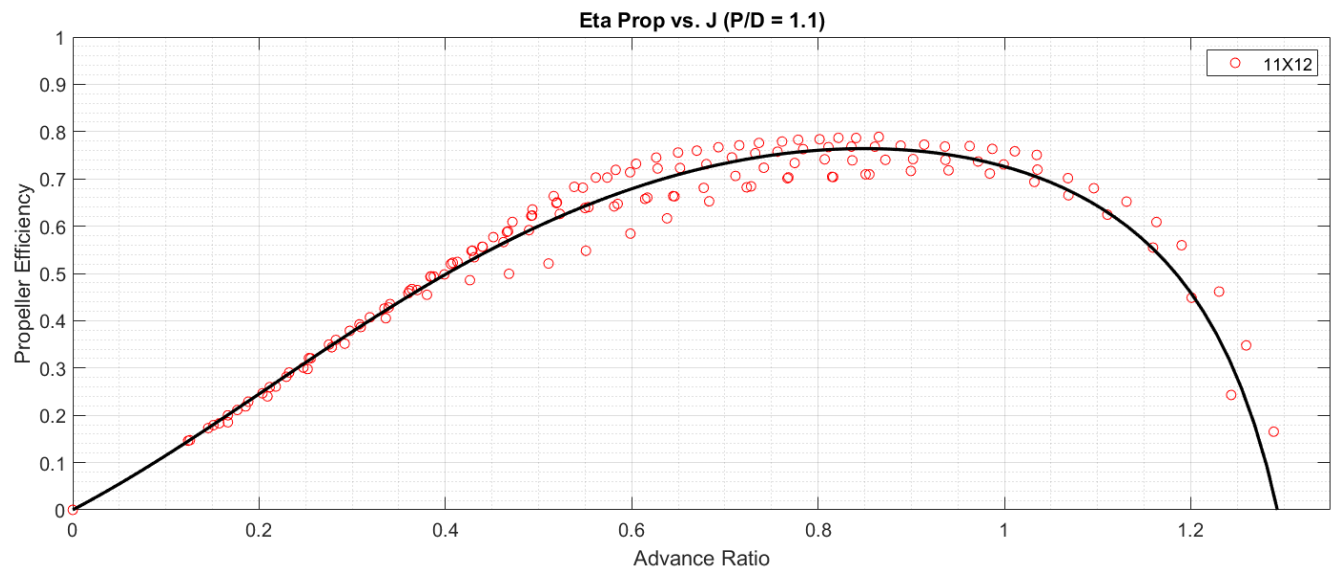

(a)

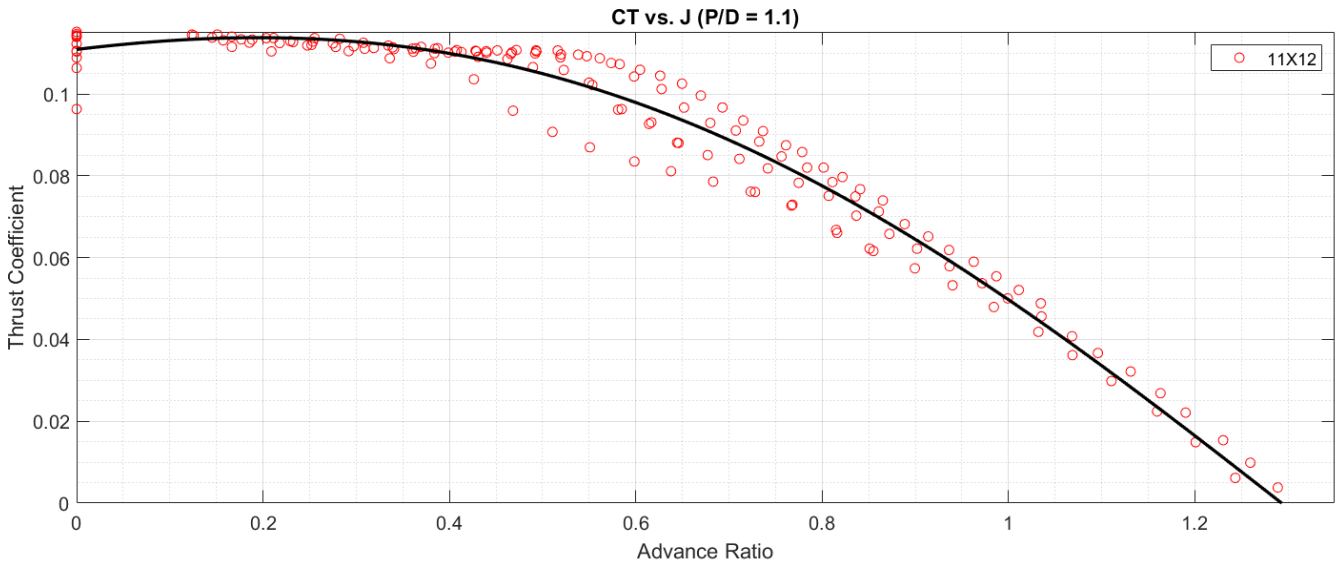

(b)

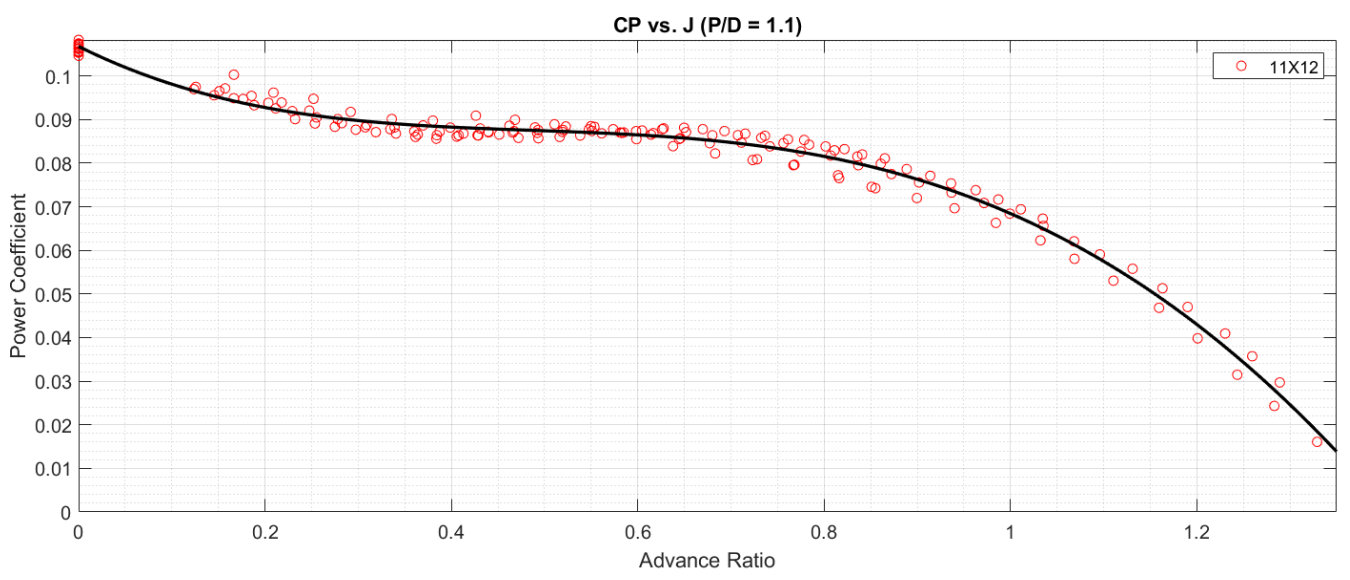

(c)

Figure 21: (a) propeller efficiency, (b) thrust coefficient, and (c) power coefficient of propeller with P/D = 1.1. 


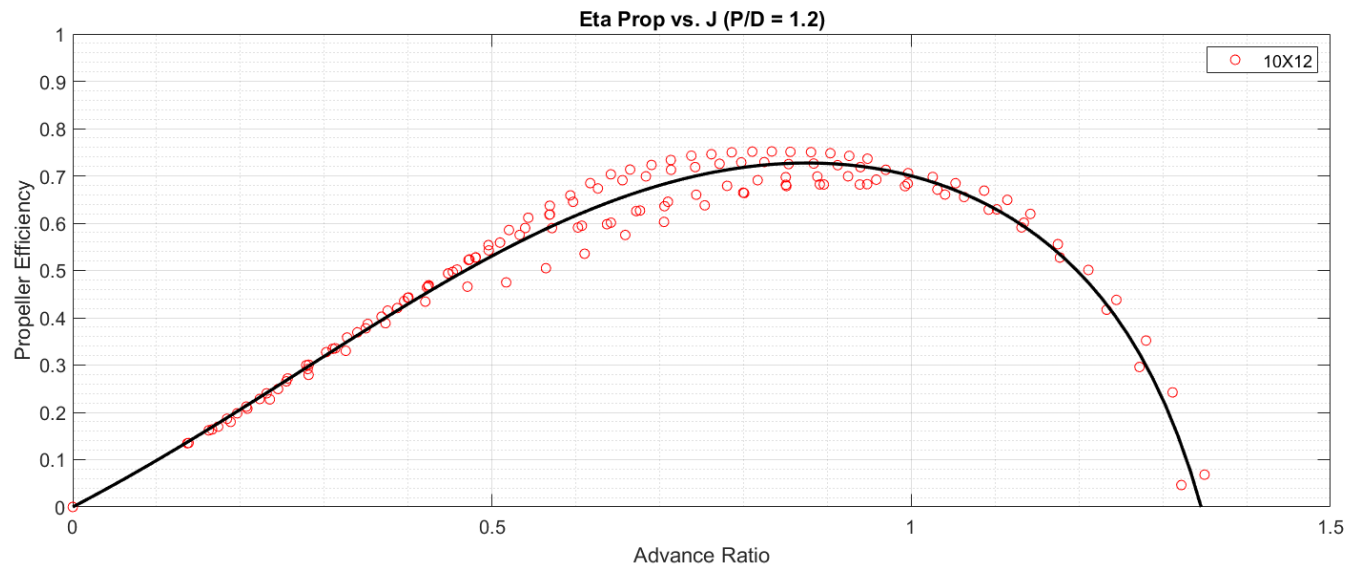

(a)

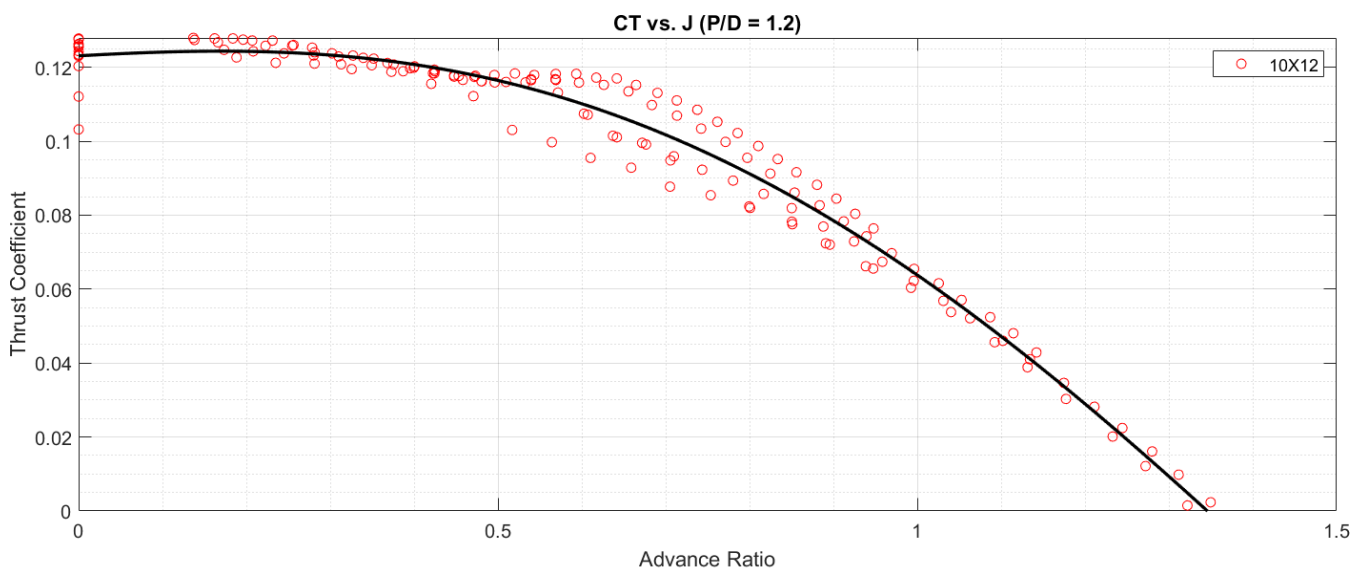

(b)

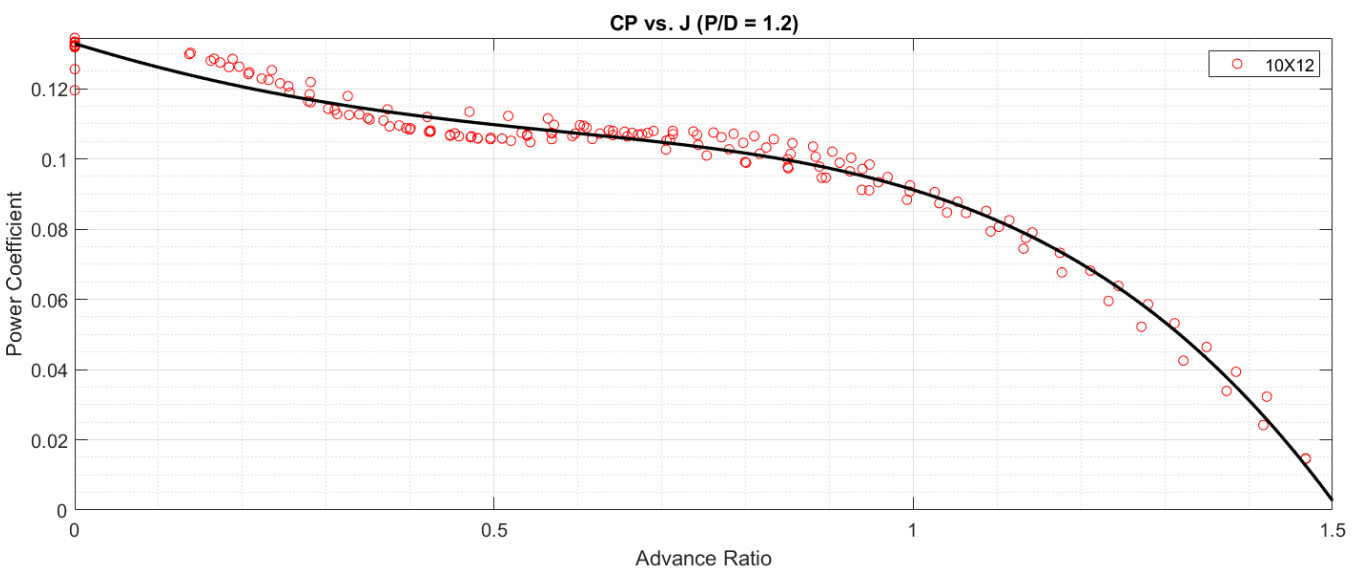

(c)

Figure 22: (a) propeller efficiency, (b) thrust coefficient, and (c) power coefficient of propeller with P/D =1.2. 